\title{
Tipificación del espacio rural a través de métodos multivariantes: ejercicio en el espacio rural malagueño
}

\author{
Remedios Larrubia Vargas ${ }^{1}$ | Susana R. Navarro Rodríguez ${ }^{2}$ \\ Recibido: 17/01/2019| Aceptado: 01/07/2019
}

\section{Resumen}

El concepto de espacio rural ha ido cambiando considerablemente en Europa desde mediados del S. XX, y con ello la integración de lo rural en la sociedad global no resulta sencilla, ni homogénea, lo que nos lleva a plantear que en cada territorio, la ruralidad se construye a partir de unas bases territoriales, culturales y productivas heterogéneas, lo que pone en evidencia que no existe una sola ruralidad. De esta forma cada territorio posee especificidades que deben ser consideras en los análisis sociales. El objetivo de este trabajo es establecer una delimitación del ámbito rural en el marco espacial de la provincia de Málaga utilizando la técnica del análisis factorial. Dicho análisis se ha complementado con un análisis clúster y una clasificación directa no sistemática, procediéndose finalmente a su comparación. El resultado final ha sido generar unas tipologías sobre el nivel de transformación productiva y el dinamismo de los municipios malagueños de menos de 20000 habitantes.

\section{Palabras clave: Análisis factorial; ruralidad; dinamismo urbano; factor; clúster}

\section{Abstract \\ Typification of rural space through multivariate methods: exercise in the rural area of Malaga}

The concept of rural space has been changing considerably in Europe since the mid-twentieth century. Due to that the integration of the rural in the global society has been neither simple nor homogeneous, which leads us to suggest that in each territory, rurality has been built from some heterogeneous territorial, cultural and productive bases. Therefore, there is no single rurality, in other words each territory has specific features that should be considered in social analyses. The aim of this paper is to establish a delimitation of the rural area in the province of Malaga using the factorial analysis technique. This analysis has been complemented by a cluster analysis and a non-systematic direct classification, which have both been compared. The final result has been to develop typologies based on the level of productive transformation and the dynamism of the municipalities of Malaga with less than 20000 inhabitants.

Keywords: Factorial analysis; rurality; urban dynamism; factor; cluster

1. Departamento de Geografía. Universidad de Málaga. rlarrubia@uma.es

2. Departamento de Geografía. Universidad de Málaga. susanros@uma.es 


\section{Introducción}

El mundo rural, como consecuencia del proceso de industrialización-urbanización acaecido desde la década de los 70 del S. XX, constituye en la actualidad un sistema que desempeña distintas funciones susceptibles de articularse de forma compleja. En este proceso la identificación exclusiva entre medio rural y producción agraria pertenece al pasado, lo rural y lo agrario son dos adjetivos con significados diferentes aunque guarden concomitancia, a la vez que la separación entre lo rural y lo urbano se hace menos evidente (Larrubia-Vargas, 1998).

En este contexto, la definición del espacio rural no resulta fácil, ya que los propios límites entre lo urbano y lo rural son difusos. No existe una definición universal de lo rural, ni definiciones oficiales compartidas por todos los países, ya sea por el tipo de criterios, o los límites cuantitativos. Destacan, además, las diferencias existentes en los marcos conceptuales y analíticos utilizados y en la calidad de los sistemas de información disponibles (Faiguenbaum, 2011).

Un tema relevante es la heterogeneidad interna de los espacios rurales que aparecerá como un inconveniente a la hora de la generalización de los métodos empleados, las variables consideradas ylos umbrales para establecer rangos. Aspectos que son evidentes cuando se examinan los criterios aplicados a nivel nacional, internacional o por autoridades científicas-académicas. Como señala Echeverri (2012), no es posible definir categóricamente «lo rural», ya que lo que se encuentra son aproximaciones a grados de ruralidad que requieren definiciones de niveles que dependen de las aproximaciones conceptuales y metodológicas que cada quien aplique de acuerdo con sus propósitos y necesidades. Ello induce a pensar que la ruralidad es un concepto multidimensional, que no puede ser analizada sino se aborda desde distintas perspectivas y/o dimensiones (LasarteLópez, et al., 2016).

Tradicionalmente para la delimitación del espacio rural, especialmente las agencias estadísticas nacionales y los organismos supranacionales, han recurrido a indicadores simples, como la densidad y el volumen demográfico o, el uso económico del territorio. El problema de estos índices radica, en general, en la dificultad para describir una realidad tan compleja en base a una única variable (Ocaña Sánchez, 2005).

Para hacer frente a estas limitaciones, así como para responder a la complejidad que ha ido asumiendo el medio rural al incorporar nuevas actividades/funciones, muchos investigadores han desarrollado índices de ruralidad sincréticos para incorporar el extenso abanico de variables que surgían al hilo de la multifuncionalidad de estos espacios.

Esta aproximación a la medición de la ruralidad tiene su inicio en la década de los 70 del siglo XX con el «índice de ruralidad para Inglaterra y Gales» (Cloke, 1977), y será seguido por investigaciones que tratan de dar cuenta del carácter multidimensional de estos espacios y que utilizan múltiples variables, entre las que cabe destacar las demográficas, socioeconómicas y de accesibilidad(Ballas et. al., 2003; Prieto y Ocaña, 2010; Pizzoli, 2014).

En el contexto de estas transformaciones, parece necesario reflexionar si los esquemas de clasificación desarrollados hasta el momento deben ser modificados con el propósito de obtener una idea más certera de lo rural en la actualidad, y con ello ofrecer mejor información para la política pública y la toma de decisiones que tenga como objetivo mejorar las condiciones de vida de su población. Este trabajo es una propuesta para medir la diversidad actual del espacio rural, tomando como marco espacial de referencia la provincia de Málaga, considerando nuevas dimensiones 
en relación a los cambios que se han venido sucediendo en los espacios rurales de las sociedades desarrolladas, y utilizando técnicas de análisis multivariante.

\section{Variables, Indicadores e Índices para medir la ruralidad}

En España, al igual que en el resto de regiones desarrolladas,se ha observado en las últimas décadas una transformación sustancial que ha redefinido las características y funciones de los espacios rurales dentro de la sociedad global. La dependencia directa del desarrollo urbano y el carácter homogéneo de las zonas rurales, definido por el predominio del sector agrario entre las actividades económicas,se están disolviendo progresivamente (Gómez-Requena, 2014), de esta forma a la tradicional producción agrícola, se han añadido las actividades relacionadas con la construcción, el turismo, la industria, el comercio, etc. (Camarero, 2009). Ante ello, como apunta Entrena-Durán (1998), se ha producido un amplio debate acerca del significado del término ruralidad y de las variables que permiten clasificar una determinada zona geográfica como tal.

El criterio más comúnmente usado en España en la delimitación del medio rural ha sido el demográfico a través de indicadores simples (volumen y densidad de población), que, por otra parte, son también los procedimientos más utilizados por los principales organismos internacionales (ONU, 1998; OCDE, 1994, 2010;Eurostat, 2012)(Cuadro 1).

En concreto, el Instituto Nacional de Estadística (INE) utiliza el tamaño de la población de los municipios españoles, planteando que los urbanos contarían con más de 10000 habitantes; mientras que la Ley 45/2007 de 13 de diciembre para el Desarrollo Sostenible del Medio Rural de España (LDSMR)considera como medio rural al espacio geográfico formado por la agregación de municipios o entidades locales menores, con población inferior a 30000 habitantes y una densidad por debajo de los 100 habitantes por $\mathrm{km}^{2}$.

Siguiendo al primer organismo el 17,2 \% de la población española vive en núcleos rurales (Goerlich et al, 2016), mientras que aplicando la consideración de la LDSMR el 90\% de la superficie española se considera rural (UAP, 2009).

A nivel académico las investigaciones llevadas a cabo con el fin de determinar nuevos índices de ruralidad han sido bastantes dispares en cuanto al tipo y número de variables utilizadas. Desde los años 80 del S. XX hay que destacar que las clasificaciones se caracterizan por su mayor complejidad puesto que los autores optan por utilizar índices compuestos (análisis multivariante basados en técnicas factoriales, análisis clúster, etc.) en los que combinan un amplio espectro de variables de carácter territorial, demográfico, social, cultural, económico y político (Cuadro 2). A nivel internacional, el número de variables que incluyen los índices de ruralidad oscilan entre 4 (Clout, 1993) y 28 (Ballas et al, 2003), pasando por las 16 del índice de Cloke(1977).

En España, y también en el ámbito de la investigación académica, han sido variados los trabajos que mediante la técnica del análisis factorial de componentes principales tipifican los municipios rurales, bien a nivel nacional (Goerlich et al, 2016) combinando tres criterios (demografía, cobertura del suelo y accesibilidad de los municipios); o a nivel regional, como los trabajos de López González et al. (2004), López y Santiago (2005), Vázquez et al (2008), Lois-González (2014), Armas-Quinta, et al (2016) etc., para Galicia que utilizan entre 6 y 46 variables; o el de Ocaña (1993) para Andalucía con 16 variables; el de Mora para Extremadura que llega a barajar 56 variables, o, el de Esparcia (2012) para la realidad valenciana a nivel municipal que con cinco variables diferenció dos grados de ruralidad. 
Cuadro 1: Indicadores y variables para delimitar lo rural a nivel institucional

\begin{tabular}{|c|c|c|c|}
\hline Instituciones & Indicadores & $\begin{array}{l}\mathrm{N}^{\circ} \\
\text { Variab }\end{array}$ & Definición y Tipología de ruralidad \\
\hline OCDE (1994) & $\begin{array}{l}\text { Demográficos:Densidad de } \\
\text { población }\end{array}$ & 1 & $\begin{array}{l}\text { Establece tres regiones: } \\
\text {-Regiones predominantemente rurales. Regiones } \\
\text { intermedias.Regiones predominantemente urbanas }\end{array}$ \\
\hline ONU (1998) & $\begin{array}{l}\text { Demográficos: Volumen de } \\
\text { habitantes }\end{array}$ & 1 & $\begin{array}{l}\text { Zonas rurales aquellas localidades con población } \\
\text { inferior a los } 2000 \text { habitantes }\end{array}$ \\
\hline UE (1999) & $\begin{array}{l}\text { Demográficos: Densidad de } \\
\text { población }\end{array}$ & & $\begin{array}{l}\text { Establece tres regiones: } \\
\text {-Urbanas. Intermedias.Rurales }\end{array}$ \\
\hline $\begin{array}{l}\text { DEMAP (Ocaña Riola } \\
\text { et al, 2005) }\end{array}$ & $\begin{array}{l}\text { Socioeconómicos y } \\
\text { demográficos }\end{array}$ & 18 & $\begin{array}{l}\text { Para España delimita tres tipos: } \\
\text {-Municipios con ruralidad alta. Municipios con ruralidad } \\
\text { baja. Municipios con ruralidad media }\end{array}$ \\
\hline $\begin{array}{l}\text { LDSMR (Ley de } \\
\text { desarrollo sostenible } \\
\text { del medio rural) (2007) }\end{array}$ & $\begin{array}{l}\text { Demográficos. Densidades, } \\
\text { Umbrales mínimo de población }\end{array}$ & 2 & $\begin{array}{l}\text { Para España establece dos grandes ámbitos: } \\
\text {-Medio rural: población inferior a } 30000 \text { habitantes y } \\
\text { densidad inferior a los } 100 \text { hab/ } / \mathrm{km}^{2} \\
\text {-Medio rural de pequeño tamaño; población residente } \\
\text { inferior a } 5000 \text { habitantes e integrado en el medio rural }\end{array}$ \\
\hline OCDE (2010) & $\begin{array}{l}\text { Demográficos: mantienen los } \\
\text { indicadores de las anteriores } \\
\text { clasificaciones } \\
\text { Cualitativos: Tiempo } \\
\text { accesibilidad conduciendo a } \\
\text { ciudad más cercana de más de } \\
5000 \text { hab. }\end{array}$ & 3 & $\begin{array}{l}\text { Establece tres regiones: } \\
\text {-Áreas predominantemente rurales y remotas. Áreas } \\
\text { predominantemente rurales pero cercanas a una } \\
\text { ciudad. Áreas intermedias cercanas a una ciudad }\end{array}$ \\
\hline INE (2011) & $\begin{array}{l}\text { Demográficos: Tamaño de } \\
\text { población }\end{array}$ & 1 & $\begin{array}{l}\text { Para España delimita tres tipos: } \\
\text {-Urbano: supera los } 10000 \text { habitantes. Intermedio: } \\
\text { entre } 2000 \text { y menos de } 10000 \text { habitantes. Rural: } \\
\text { menos de } 2000 \text { habitantes }\end{array}$ \\
\hline $\begin{array}{l}\text { OCDE, EUROSTAT, } \\
\text { DG-REGIO (2012) }\end{array}$ & $\begin{array}{l}\text { Demográficos: Densidad y } \\
\text { tamaño demográfico mínimo* }\end{array}$ & 2 & $\begin{array}{l}\text { Clasifica como áreas rurales aquellas zonas que } \\
\text { quedan excluidas fuera de la aglomeraciones urbanas, } \\
\text { estableciendo dos tipos: } \\
\text {-Urban clusters(densidad mínima } 300 \text { hab/km2, } \\
\text { población mínima } 5000 \text { habitantes) } \\
\text {-High density (densidad mínima } 1500 \text { hab/km2,umbral } \\
\text { mínimo de población } 50000 \text { habitantes) }\end{array}$ \\
\hline
\end{tabular}

*. Como unidad territorial de análisis considera el grid de población con resolución de 1 km2 Fuente: VV.AA. Elaboración propia. 
Cuadro 2: Indicadores y variables para delimitar lo rural en el ámbito académico- científico

\begin{tabular}{|c|c|c|c|}
\hline Investigador & Indicadores & $\mathrm{N}^{\circ}$ Vari. & Definición y Tipología de ruralidad \\
\hline CLOKE (1977) & $\begin{array}{l}\text { Demográficos, Ocupación, } \\
\text { Distancia centros urbanos }\end{array}$ & 16 & $\begin{array}{l}\text { Establece cinco clase que van desde el rural extremo } \\
\text { a áreas urbanas }\end{array}$ \\
\hline MORA-ALISEDA (1991) & $\begin{array}{l}\text { Físico-natural, } \\
\text { Socioeconómico, } \\
\text { Demográfico, Nivel de } \\
\text { vida, Equipamientos e } \\
\text { infraestructuras }\end{array}$ & 56 & $\begin{array}{l}\text { Para Extremadura diferencia } 4 \text { niveles de } \\
\text { asentamientos según indicadores urbanos y } \\
\text { demográficos (urbano, urbanizado, semi-rural, rural) } \\
\text { Según indicadores demográficos delimita otros cuatro } \\
\text { (asentamientos muy dinámicos, dinámicos, menos } \\
\text { dinámicos y regresivos. }\end{array}$ \\
\hline CLOUT (1993) & $\begin{array}{l}\text { Densidad de población } \\
\text { baja, Escases de } \\
\text { infraestructuras, Pocos } \\
\text { trabajadores en el } \\
\text { secundario y terciario, Uso } \\
\text { predominante agrícola }\end{array}$ & 4 & $\begin{array}{l}\text { Establece tres áreas a nivel europeo: } \\
\text { Áreas rurales dinámicas. Áreas rurales periféricas con } \\
\text { bajos niveles de desarrollo económico y social. Áreas } \\
\text { rurales en proceso de abandono. }\end{array}$ \\
\hline OCAÑA-OCAÑA(1993) & $\begin{array}{l}\text { Demográficos, Ocupación, } \\
\text { Renta }\end{array}$ & 16 & $\begin{array}{l}\text { Para Andalucía establece } 6 \text { tipos: } \\
\text { Rural profundo. Rural tradicional periurbano. Rural } \\
\text { evolucionado. Rural evolucionado en declive. Fuerte } \\
\text { dinámica urbana }\end{array}$ \\
\hline BALLAS et al. (2003) & $\begin{array}{l}\text { Socioeconómicas y } \\
\text { demográficas }\end{array}$ & 28 & Múltiples tipologías de ruralidad (18 tipos) \\
\hline $\begin{array}{l}\text { LÓPEZ- GONZÁLEZ et } \\
\text { al. (2004) }\end{array}$ & $\begin{array}{l}\text { Medio físico, Población, } \\
\text { Poblamiento, } \\
\text { Actividad económica, } \\
\text { Sociales, Sector } \\
\text { agrario, Edificaciones, } \\
\text { Accesibilidad }\end{array}$ & 46 & $\begin{array}{l}\text { Delimita cinco tipos de municipios para Galicia } \\
\text { Los situados en las zonas muy urbanizadas, los de } \\
\text { gran atractivo turístico, los que presentan actividades } \\
\text { diversificadas, los que tienen un predominio agrícola, y } \\
\text { los de difícil acceso o marginales }\end{array}$ \\
\hline $\begin{array}{l}\text { LÓPEZ-RATÓN, et al } \\
(2005)\end{array}$ & $\begin{array}{l}\text { Población, Ocupación, } \\
\text { Cualificación }\end{array}$ & 15 & $\begin{array}{l}\text { Para Galicia, establece tres tipos: } \\
\text { Urbano. Semiurbano. Rural }\end{array}$ \\
\hline WALDORF (2006) & $\begin{array}{l}\text { Tamaño y densidad de } \\
\text { población, Extensión del } \\
\text { área urbana, Lejanía o } \\
\text { perificidad }\end{array}$ & 4 & $\begin{array}{l}\text { Para Estados Unidos establece una gradación de } \\
\text { áreas desde las más urbanas (0) a las más rurales (1) }\end{array}$ \\
\hline VAZQUEZ et al. (2008) & $\begin{array}{l}\text { Demografía, Ocupación, } \\
\text { Usos del suelo, Vivienda, } \\
\text { Estructura explotaciones, } \\
\text { Economía, Empresarial }\end{array}$ & 16 & $\begin{array}{l}\text { Establece } 4 \text { tipos: } \\
\text { Rural diversificado. Rural con productividad alta. Rural- } \\
\text { agrario con productividad media. Rural-agrario con } \\
\text { productividad baja }\end{array}$ \\
\hline ESPARCIA (2012) & Demográficos y ocupación & 5 & $\begin{array}{l}\text { Para Valencia: } \\
\text { Índice ruralidad alta ( } 4 \text { o } 5 \text { variables) } \\
\text { Índice ruralidad baja( } 1 \text { de las } 5 \text { variables) }\end{array}$ \\
\hline LOIS-GONZÁLEZ (2014) & $\begin{array}{l}\text { Densidades de población, } \\
\text { Actividad agraria, } \\
\text { Distancia a las áreas } \\
\text { urbanas }\end{array}$ & 3 & $\begin{array}{l}\text { Establece tres áreas para Galicia } \\
\text { Áreas rurales con un efectivo humano aún destacado. } \\
\text { Áreas con elevado grado de despoblación y } \\
\text { envejecimiento. Áreas que aún conserva un sustrato } \\
\text { agrario significativo. }\end{array}$ \\
\hline GROERLICH et al. (2016) & $\begin{array}{l}\text { Demografía, usos del } \\
\text { suelo, accesibilidad }\end{array}$ & 3 & $\begin{array}{l}\text { Para España establece } 6 \text { tipos: } \\
\text { Rural remoto. Rural accesible. Intermedio cerrado. } \\
\text { Intermedio abierto. Urbano cerrado Urbano abierto. }\end{array}$ \\
\hline ARMAS et al. (2017) & $\begin{array}{l}\text { Población, Viviendas, } \\
\text { Población en el sector } \\
\text { agrario, Tiempo } \\
\text { desplazamiento a núcleos } \\
\text { urbanos }\end{array}$ & 6 & $\begin{array}{l}\text { Para Galicia establece } 5 \text { tipos: } \\
\text { Urbano, Semiurbano, Semi-rural, Rural, Muy rural. }\end{array}$ \\
\hline
\end{tabular}

Fuente: VV.AA. Elaboración propia. 


\section{Fuente y metodología. Variables seleccionadas}

En el análisis factorial el acierto en la selección de las variables es fundamental para que los resultados sean certeros y útiles. Es evidente que aquellas deben estar relacionadas probabilísticamente con las áreas claves de la diversidad rural; igualmente sus valores tienen que ofrecer una variabilidad territorial que permita identificar las diferencias entre las poblaciones estudiadas, y por último, también es necesario que tengan un nivel de correlación válido para poder reducirlas a indicadores sintéticos utilizando el análisis factorial.

La identificación de las variables estadísticas como indicadores geográficos (es decir, la puntuación que merece una variable como atributo de un criterio concreto), ha contado con un trabajo previo de análisis de las variables con desagregación municipal (demográficas, sociales, de actividad, de renta, de riqueza, de equipamientos etc.) a partir del banco de datos IECA (Instituto de Estadísticay Cartografía de Andalucía) para Andalucía.En ese barrido, se partió de una selección muy amplia de las variables contenidas en dicho banco de datos que van desde caracteres territoriales, a las de renta, pasando por economía, dotaciones etc. a fin de explorar sus correlaciones y su posible utilidad para el análisis socio-espacial.

Como resultado de ese análisis previo quedaron descartadas una proporción muy elevada de las variables. En general se desecharon todas aquellas que no mostraban correlaciones significativas con otras variables de carácter social o económico (por ejemplo, en una primera eliminación se excluyeron de entrada las relacionadas con las dotaciones de equipamientos de servicios socialesescolares, recreativos, transportes, de salud, etc.- no por carecer de interés sino por su funcionamiento entre el conjunto de la información, pues su correlaciónen valores relativos sean por habitantes, o por índices de especialización, son muy débiles con la restante información). Y también con carácter general se excluyeron todas aquellas (algunas de indudable interés) con vacíos apreciables por causa de secreto estadístico, que constituye otra de las limitaciones de la información más desagregada espacialmente y que penaliza en el análisis municipal a los de menor población.

Otras fuentes de información complementarias han sido: en primer lugar, el Censo de población de 2011, queaunque desfasada su información, se mostraba necesario para cubrir algunos vacíos importantes, como el referido a la información actual sobre el nivel de estudios. Como la estructura, por niveles educativos, ya estaba muy evolucionada en 2011 respecto a unas décadas anteriores, no tiene que resultar discordante con la situación actual. También, aunque con más reservas, se ha adoptado de dicha fuente información sobre la situación profesional y la variable» vivienda secundaria» ( $\mathrm{n}^{\circ}$ por 100 residentes) como expresión de un parque de viviendas que excede a la población local. En segundo lugar, las estadísticas del Ministerio de empleo y seguridad social (MESS), sobre afiliados en alta y número de contratos (Servicio Público de Empleo), en ambos casos referidos a las localidades en que se registra la actividad.

Como aparece en el cuadro3 y de acuerdo a experiencias anteriores (Ocaña, 1993) el resultado final ha sido la selección de 21 variables $^{3}$ pertenecientes a 7 ejes temáticos que se sustentan, a su vez, en varios indicadores.

3. Respecto a las variables una anotación: no se ha incluido el volumen de población a fin de que no condicione los resultados del análisis. Se ha valorado de más interés la comprobación posterior de cómo se ajustan los factores obtenidos con las diferentes categorías de asentamientos, y las posibles diferencias que en esta relación puedan reconocerse por ámbitos geográficos. 
Cuadro 3. Variables seleccionadas

\begin{tabular}{|c|c|c|}
\hline EJES TEMÁTICOS & INDICADORES & VARIABLES \\
\hline \multirow[t]{3}{*}{ Dinamismo urbano } & \multirow[t]{2}{*}{ Población } & Incremento relativo de la población en diez años (2016) (IECA) \\
\hline & & Saldo migratorio. Tasa media (2012-2016) (IECA) \\
\hline & Vivienda & Vivienda Secundaria ( $\mathrm{n} / 100$ hab.) (Censo 2011) \\
\hline \multirow[t]{3}{*}{ Modelo demográfico } & \multirow[t]{2}{*}{ Tasas vitales } & Tasa de natalidad (media 2012-2016) (IECA) \\
\hline & & Tasa de mortalidad (media 2012-2016) (IECA) \\
\hline & Estructura por edad & < de 15 años por 100 habitantes de > 65 años (padrón 2017) \\
\hline \multirow[t]{2}{*}{ Evolución social } & \multirow[t]{2}{*}{ Estudios } & Sin estudios (\% sobre mayores de 16 años (Censo 2011) \\
\hline & & $\begin{array}{l}\text { Con estudios universitarios (\% sobre mayores de } 16 \text { años } \\
\text { (Censo 2011) }\end{array}$ \\
\hline \multirow[t]{5}{*}{ Mercado de trabajo } & Solidez & Asalariado fijo (\% sobre total activo) (Censo 2011) \\
\hline & \multirow[t]{2}{*}{ Precariedad } & Asalariado eventual (5 sobre total activo) (Censo 2011) \\
\hline & & Trabajadores agrarios subsidiados ( $n^{\circ}$ por 100 hab.) (IECA) \\
\hline & Déficit & Tasa media de paro (2016) (SEPE) \\
\hline & Movilidad & $\begin{array}{l}\text { Afiliaciones población local/Afiliaciones población residente } \\
\text { (2016) (SEPE) }\end{array}$ \\
\hline \multirow[t]{5}{*}{ Estructura actividad } & \multirow[t]{2}{*}{ Por contratos } & $\%$ Contratos en Agricultura y Pesca (2016) (SEPE) \\
\hline & & $\%$ Contratos en Servicios (2016) (SEPE) \\
\hline & \multirow[t]{3}{*}{ Por ocupados } & \% Afiliados R.G. Seguridad Social (2016) (SEPE) \\
\hline & & \% Afiliados Régimen Especial Agrario (2016) (SEPE) \\
\hline & & $\begin{array}{l}\text { Altas en actividades profesionales ( } n^{\circ} \text { por } 100 \text { hab.) (2015) } \\
\text { (SEPE) }\end{array}$ \\
\hline \multirow{3}{*}{$\begin{array}{l}\text { Ingresos sociales no } \\
\text { productivos }\end{array}$} & Pensionistas & Pensionistas ( $\mathrm{n}^{\circ}$ por 100 habitantes) (2016) (MESS) \\
\hline & Pensiones & Pensión media (2016) (MESS) \\
\hline & Renta & Renta media neta declarada (2016) (IECA) \\
\hline
\end{tabular}

Fuente: IECA (Instituto de Estadística y Cartografía de Andalucía. Censo Población (2011). Estadísticas del MTMSS. Elaboración propia.

A fin de identificar la heterogeneidad de los espacios rurales se ha recurrido a métodos multivariante, en primer lugar, a través del análisis factorial se ha procedido a identificar los ejes fundamentales de la diversidad rural. En segundo lugar, a través de un análisis clúster y una clasificación directa supervisada, se ha obtenido dos tipologías de los núcleos rurales, finalizándose el planteamiento metodológico con la comparación de ambas clasificaciones.

El ámbito de aplicación de esta investigación sobre la tipificación de la ruralidad es la provincia de Málaga. Una provincia con una extensión de 7308 km², con 103 municipios y 1630615 habitantes en 2017. En cuanto a su organización territorial, en ella podemos diferenciar regiones con caracteres propios, identificadas con las demarcaciones tradicionales (comarcas) del Ministerio de Agricultura. En la zona norte, la comarca de Antequera, al este la de la Axarquía, al oeste la Serranía de Ronda y al sur la del Guadalhorce, a la que se añade la banda litoral (Figura1). 
Figura 1. Localización geográfica del área de estudio. Provincia de Málaga.

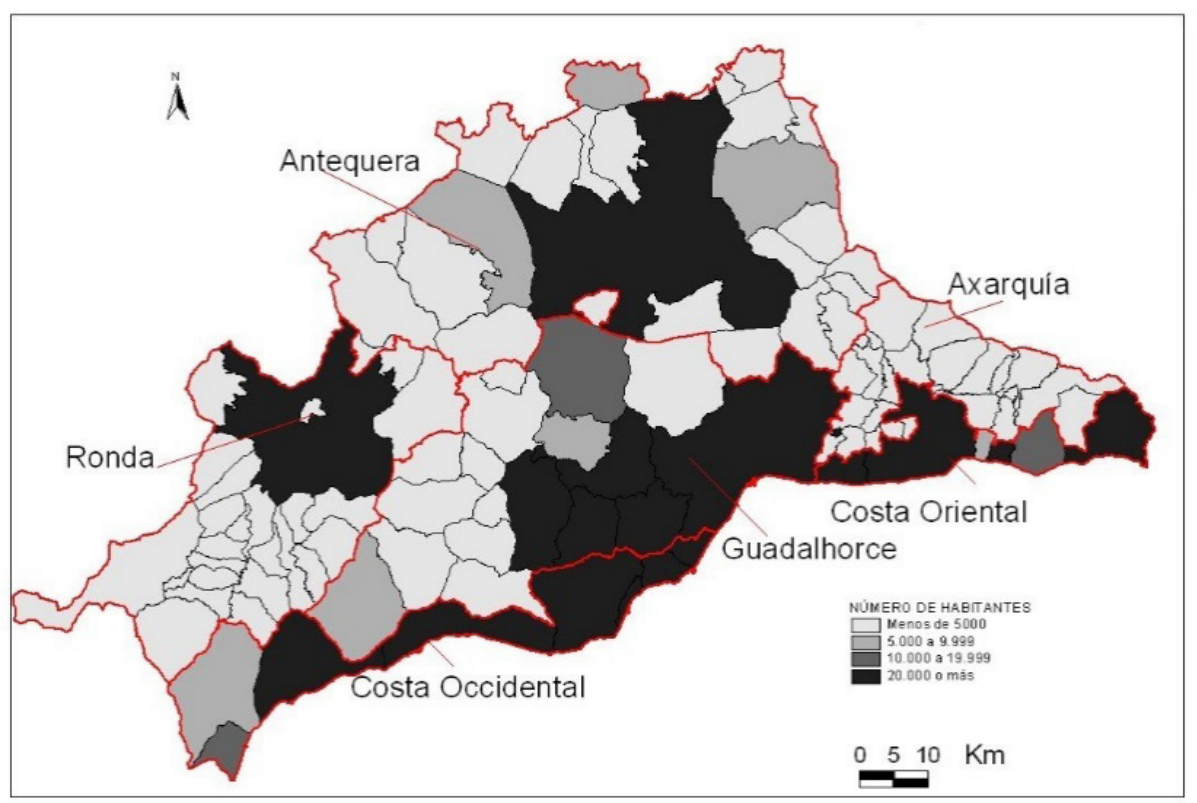

Fuente: Padrón de habitantes de 2017.

Los municipios delimitados en el estudio son los menores a 20000 habitantes (Cuadro 4), lo que deja fuera las cabeceras comarcales de Antequera y la Axarquía, los municipios del bajo Guadalhorce y la mayor parte del litoral que, a consecuencia del intenso desarrollo urbano, ya no pueden considerarse como rural por el alto volumen de sus poblaciones y la diversificación de sus actividades económicas.Cabría pensar que aquellos contrastes que se detectaron entre los pueblos hace un par de décadas y que tenían su origen en dichos factores, no sean tan relevantes en el momento actual, por quedar pocos municipios en el ámbito costero o periurbano que no rebasen los 20000 habitantes. De esta forma esperamos que nuestro análisis ofrezca una realidad probablemente con diferencias más sutiles y ligadas a factores internos.

Cuadro 4. Municipios de $<20000$ habitantes. Distribución comarcal

\begin{tabular}{|c|c|c|c|c|c|c|c|c|}
\hline & \multirow{2}{*}{ Antequera } & \multirow{2}{*}{ Ronda } & \multirow{2}{*}{ Guadalhorce } & \multirow{2}{*}{ Axarquía } & \multirow{2}{*}{$\begin{array}{l}\text { Costa } \\
\text { Occidental }\end{array}$} & \multirow{2}{*}{$\begin{array}{l}\text { Costa } \\
\text { Oriental }\end{array}$} & \multicolumn{2}{|l|}{ Total } \\
\hline & & & & & & & Núm. & $\%$ \\
\hline$<1000$ & 1 & 16 & 1 & 9 & 0 & 0 & 27 & 32,14 \\
\hline $\begin{array}{l}1000 \mathrm{a} \\
5000\end{array}$ & 16 & 6 & 9 & 13 & 2 & 0 & 46 & 54,76 \\
\hline $\begin{array}{l}5000 \mathrm{a} \\
10000\end{array}$ & 4 & 0 & 1 & 0 & 2 & 1 & 8 & 9,52 \\
\hline$>10000$ & 0 & 0 & 1 & 0 & 1 & 1 & 3 & 3,57 \\
\hline Total & 21 & 22 & 12 & 22 & 5 & 2 & 84 & 100 \\
\hline Habitantes & 74599 & 20643 & 45675 & 33135 & 32620 & 21665 & 228337 & \\
\hline
\end{tabular}

Fuente: Padrón de habitantes, 2017. INE. 


\section{El análisis factorial:Significado de cada factor e identificación de tipos de ruralidad}

El conjunto de las variables seleccionadas, 21 en total, presentan unos niveles de correlación significativamente altos, de modo que constituyen un conjunto de datos adecuados para buscar su síntesis mediante un análisis factorial.

El análisis factorial se ha realizado dentro del programa SPSS, mediante el método de «extracción de componentes principales», con rotación "varimax», seleccionando solo los factores de valor superior a 1, complementado con la prueba KMO para validar los resultados del análisis, dando un valor de 0,765 .

A la vista de estos parámetros los resultados son satisfactorios. Han aparecido 4 factores todos con cierto peso (con valores propios, mayor a 3 en todos los casos) que conjuntamente explican el 75,3\% de la varianza (Cuadro 5). Como síntesis de la información hay que calificar el ejercicio como muy eficiente. Y por lo que respecta a las variables, la comunalidad es elevada, oscilando entre 0,8 y 0,5, de lo que se desprende que ninguna de ellas está desconectada de estos cuatro factores (Cuadro 6). Por otra parte, tras la rotación varimax, la estructura factorial ha resultado muy definida (apenas dos variables son significativas en más de un factor) de modo que no resultan confusos en su interpretación.

Cuadro 5: Autovalores y varianza (factores rotados)

\begin{tabular}{|l|l|l|l|}
\hline Factor & Autovalores & $\begin{array}{l}\% \text { de la } \\
\text { varianza }\end{array}$ & $\begin{array}{l}\% \\
\text { acumulado }\end{array}$ \\
\hline 1 & 4,3 & 20,7 & 20,7 \\
\hline 2 & 4,0 & 19,0 & 39,6 \\
\hline 3 & 3,6 & 17,0 & 56,6 \\
\hline 4 & 3,1 & 14,7 & 71,3 \\
\hline
\end{tabular}

Fuente: IECA (Instituto de Estadística y Cartografía de Andalucía. Censo Población (2011). Estadísticas del MESS (Ministerio de Empleo y Seguridad Social). Elaboración propia.

El significado de cada factor como nueva variable se desprende de los coeficientes de correlación de las variables iniciales con cada uno de ellos. Elconjuntode estos coeficientes forman la estructura factorial o matriz de cargas (Cuadro 6)

Cuadro 6. Matriz de cargas factoriales y Comunalidad

\begin{tabular}{|l|l|l|l|l|l|}
\hline \multirow{2}{*}{ Variables } & \multirow{2}{*}{ Comunalidad } & \multicolumn{2}{l|}{ Cargas Factoriales } \\
\cline { 3 - 7 } & & 10 & $2^{\circ}$ & $3^{\circ}$ & $4^{\circ}$ \\
\hline Incremento relativo de la población en diez años (2016) & 0,878 & 0,27 & 0,38 & 0,80 & $-0,12$ \\
\hline Saldo migratorio. Tasa media (2012-2016) & 0,794 & 0,26 & 0,34 & 0,76 & $-0,16$ \\
\hline Vivienda secundaria (\%) & 0,81 & $-0,05$ & $-0,23$ & $-0,11$ & 0,86 \\
\hline Tasa de natalidad (2012-2016) & 0,654 & 0,03 & 0,80 & $-0,07$ & 0,01 \\
\hline Tasa de mortalidad (2012-2016) & 0,541 & $-0,04$ & $-0,69$ & $-0,25$ & 0,02 \\
\hline$<15$ años por 100 habitantes >65 años (padrón 2017) & 0,842 & 0,05 & 0,90 & 0,13 & $-0,09$ \\
\hline
\end{tabular}




\begin{tabular}{|c|c|c|c|c|c|}
\hline \multirow{2}{*}{ Variables } & \multirow{2}{*}{ Comunalidad } & \multicolumn{4}{|c|}{ Cargas Factoriales } \\
\hline & & $1^{\circ}$ & $2^{\circ}$ & $3^{\circ}$ & $4^{\circ}$ \\
\hline Sin estudios (\%) (Censo 2011) & 0,507 & $-0,20$ & $-0,52$ & $-0,40$ & 0,19 \\
\hline Con estudios universitarios (\%) (censo 2011) & 0,416 & 0,11 & 0,51 & 0,33 & $-0,20$ \\
\hline Asalariado fijo & 0,821 & 0,18 & 0,25 & 0,07 & $-0,85$ \\
\hline Asalariado eventual & 0,809 & $-0,08$ & 0,11 & $-0,23$ & 0,86 \\
\hline Trabajadores agrarios subsidiados por 100 habitantes & 0,703 & 0,43 & 0,05 & $-0,71$ & 0,08 \\
\hline Tasa media de paro & 0,754 & $-0,78$ & $-0,09$ & $-0,06$ & 0,37 \\
\hline Afiliaciones locales/afiliaciones residentes & 0,728 & $-0,84$ & 0,11 & $-0,05$ & $-0,12$ \\
\hline$\%$ Contratos agricultura y pesca & 0,655 & 0,77 & 0,12 & $-0,11$ & 0,17 \\
\hline$\%$ Contratos en servicios & 0,741 & 0,75 & 0,20 & 0,21 & $-0,32$ \\
\hline \% Afiliados al R.G de la Seguridad Social & 0,896 & $-0,84$ & $-0,23$ & $-0,17$ & 0,33 \\
\hline$\%$ Afiliados al Régimen Especial Agrario & 0,486 & 0,35 & 0,38 & 0,39 & $-0,26$ \\
\hline Alta en actividades profesionales, por 100 habitantes & 0,849 & 0,01 & 0,14 & 0,90 & $-0,11$ \\
\hline $\mathrm{N}^{\circ}$ de pensionistas, por 100 habitantes & 0,691 & $-0,36$ & $-0,59$ & $-0,39$ & 0,25 \\
\hline Pensión media & 0,572 & 0,55 & 0,41 & 0,10 & $-0,30$ \\
\hline Renta neta media declarada & 0,83 & 0,43 & 0,56 & 0,43 & $-0,38$ \\
\hline
\end{tabular}

Fuente: IECA (Instituto de Estadística y Cartografía de Andalucía. Censo Población (2011). Estadísticas del MESS (Ministerio de Empleo y Seguridad Social). Elaboración propia.

De la matriz de cargas se desprende que el Factor $1^{\circ}$, que resume un $20 \%$ de la varianza, tiene coeficientes altos con las variables relacionadas con la estructura de actividad, y también, aunque con coeficientes menores con otras tres variables: «pensión media» $(0,548)$, «renta neta media declarada» $(0,433)$ y «tasa media de paro» $(0,431)$.

La asociación negativa de las variables de actividad agraria con las variables relacionadas con las actividades no agrarias y concretamente a los servicios justifica su identificación como «transformación productiva»en el sentido de menor dependencia agraria. La relación positiva de otras variables ( "pensión media» $\mathrm{y}$ «renta media declarada») aporta perfiles económicos positivos al sentido de este factor. Sin embargo, el signo positivo de la variable «tasa de desempleo» señala un matiz en la interpretación del factor que se hará patente en otras fases del análisis.

El Factor $2^{\circ}$ explica una proporción de la varianza casi similar. Tiene en él coeficientes muy altos las variables introducidas como indicadores del modelo demográfico, y arrastra caracteres del modelo social como el nivel educativo, porque todavía tiene cierta dependencia según las poblaciones con la estructura de edad, e igualmente con la variable "pensionistas» por su natural relación con el envejecimiento. La interpretación del factor está muy determinada por una variable, la «proporción de menores sobre ancianos» con un coeficiente de 0,902 . Apoyado por la tasa de natalidad se identifica como un claro indicador de «buen estatus demográfico» que se corrobora con el coeficiente negativo de la tasa de mortalidad.

El Factor $3^{\circ}$ explica una varianza de $17 \%$ y está muy definido por cuatro variables con coeficientes muy altos. Tres de estos coeficientes son positivos: los de las variables «incremento de la población en la década anterior», "tasa media de crecimiento migratorio» $\mathrm{y}$ "ratio entre afiliados locales y afiliados residentes». El cuarto coeficiente alto es negativo y corresponde a la «tasa media de desempleo». La interpretación de este factor como «dinamismo local»estaría justificado por el coeficiente alto de la variable crecimiento de población y el sentido de atracción que incorpora el 
crecimiento migratorio, y la variable ratio entre afiliados por lugar de empleo y afiliados por lugar de residencia, que es el mayor de todos $(0,904)$. Similar sentido positivo se apoya en el coeficiente alto y negativo de la tasa de paro (es el factor más determinado en esta variable), que asocia el dinamismo con el menor déficit del mercado de trabajo. También los otros coeficientes menores apoyan el sentido de desarrollo que apunta este factor ${ }^{4}$.

El Factor $4^{\circ}$ tiene un peso menor (14\% de la varianza), y está definido por tres altos coeficientes con las variables: «vivienda secundaria», «asalariados eventuales» y «asalariados fijos». Ninguna otra variable tiene significado en el factor. Tal asociación identifica situaciones de «ocupación precaria y viviendas de ocupación temporal». Este factor no será tenido en cuenta para la posterior construcción de una tipología debido, en parte, a la ambigua interpretación que se ha advertido en la distribución espacial de las viviendas secundariasy sobre todo porque el factor viene forzado por la asociación negativa y constante de la variable trabajadores fijos con trabajadores eventuales.

\section{Asociación entre las puntuaciones de los factores}

El método de análisis aplicado, el de componentes principales, implica que los factores extraídos son variables no correlacionadas, de modo que no cabe esperar ninguna regularidad en términos estadísticos de sus correlaciones espaciales. Sin embargo, en el camino hacia la posible definición de una tipología en razón de los valores de cada factor, se ha efectuado un análisis previo de cómo se combinan entre sí. Se han realizado tres combinaciones de factores (Factores $1^{\circ}$ y $2^{\circ}$, Factores $1^{\circ}$ y $3^{\circ}$ y Factores $2^{\circ}$ y $3^{\circ}$ ), pero la última combinación se ha convertido en un ejercicio fallido en cuanto a descubrir lazos entre los factores.

\subsection{Combinación de los valores delos Factores $1^{\circ}$ y $2^{\circ}$}

Resulta muy reveladora la combinación del Factor $1^{\circ}$ y el Factor $2^{\circ}$ para observar las relaciones no aleatorias, pero tampoco regulares, que se puede advertir entre el grado de «transformación productiva» y los niveles del «estatus demográfico/social» según las áreas geográficas y la categoría de los asentamientos.

Para este propósito las puntuaciones han de agregarse en clases. Como punto de partida se establecieron cuatro intervalos, por debajo o por encima de una desviación típica, en los valores positivos y en los negativos que originaron 16 categorías todas ellas efectivas. La gran dispersión de las observaciones entre las categorías indujo a plantear una clasificación con menor número de clases. Se establecieron dos para el Factor $1^{\circ}$, las positivas y las negativas, aprovechando que ofrecen pocas puntuaciones bajas. En el caso del Factor $2^{\circ}$, con bastante amplitud de las puntuaciones bajas, se establecieron tres clases: dos de ellas para las puntuaciones destacadas, positivas o negativas respectivamente ( $\mathrm{de}>0,0$ o de $<-0,5$ ), y una clase para las menos definidas (las puntuaciones que se aproximan a 0 , es decir de 0,5 a -0,5). A partir de aquí se han establecido seis categorías (Cuadro 7).

4. En el análisis de sus puntuaciones se advierte que el sentido del factor se desvirtúa en muchas poblaciones pequeñas, porque el paro o la atracción de ocupados, refleja, en estos casos, simples carencias locales: pocos activos y la residencia en otros municipios de algunos de sus ocupados. 
Los 84 municipios se distribuyen con bastante uniformidad entre las seis categorías establecidas por la asociación de los Factores $1^{\circ}$ y $2^{\circ}$, si bien destaca entre ellas la «E» como la más frecuente. Sin embargo, la población que representan los municipios asignados a cada categoría muestra contrastes más altos, debido a que existecierta asociación entre las categorías y los tamaños de los municipios.

Cuadro 7. Categorías, población y municipios de la combinación del Factor $1^{\circ}$ y el Factor $2^{\circ}$

\begin{tabular}{|l|l|l|l|l|l|}
\hline \multicolumn{2}{|l}{$\begin{array}{l}\text { Categorias: combinatoria Factores } 1^{\circ} \text { y } 2^{\circ} \\
N^{\circ}\end{array}$} & \multicolumn{2}{l}{ Municipios } & \multicolumn{2}{l|}{ Población } \\
\cline { 3 - 6 } \multicolumn{2}{l}{} & $\%$ & Habit. & $\%$ & \\
\hline A & Actividad transformada y estatus demográfico alto & 12 & 14,3 & 68615 & 30,0 \\
\hline B & Actividad transformada y estatus demográfico medio & 11 & 13,1 & 39691 & 17,4 \\
\hline C & Actividad transformada y estatus demográfico bajo & 11 & 13,1 & 5390 & 2,4 \\
\hline D & Actividad no transformada y estatus demográfico alto & 14 & 16,7 & 57477 & 25,2 \\
\hline E & Actividad no transformada y estatus demográfico medio & 20 & 23,8 & 40975 & 17,9 \\
\hline F & Actividad no transformada y estatus demográfico bajo & 16 & 19,0 & 16189 & 7,1 \\
\hline & & 84 & 100 & 228337 & 100 \\
\hline
\end{tabular}

Fuente: IECA (Instituto de Estadística y Cartografía de Andalucía. Censo Población (2011). Estadísticas del MESS (Ministerio de Empleo y Seguridad Social). Elaboración propia.

Confirmando esta asociación cabe destacar que los municipios más pequeños, los de menos de 1000 habitantes, se clasifican mayoritariamente en las categorías «C» $\mathrm{y}$ « $\mathrm{F}$ », que coinciden ambas en su bajo estatus demográfico, aunquese localizan más en la primera de ellas, la de estructura de actividad transformada. Por oposición, los pueblos mayores, de 5000 a 10000 habitantes,se vinculan preferentemente con la categoría «D»; y en la categoría «A» están incluidos los tres municipios de más de 10000 habitantes (Cuadro8).

Cuadro 8. Frecuencia relativa por tamaño de municipios de cada categoría de la combinación del Factor $1^{\circ}$ y el Factor $2^{\circ}$

\begin{tabular}{|c|c|c|c|c|c|c|c|}
\hline \multirow{2}{*}{ Población } & \multicolumn{7}{|l|}{ Categorías } \\
\hline & A & B & C & D & E & $\mathrm{F}$ & \\
\hline & $\begin{array}{l}\text { Actividad } \\
\text { transformada } \\
\text { y estatus } \\
\text { demográfico } \\
\text { alto }\end{array}$ & $\begin{array}{l}\text { Actividad } \\
\text { transformada } \\
\text { y estatus } \\
\text { demográfico } \\
\text { medio }\end{array}$ & $\begin{array}{l}\text { Actividad } \\
\text { transformada } \\
\text { y estatus } \\
\text { demográfico } \\
\text { bajo }\end{array}$ & $\begin{array}{l}\text { Actividad no } \\
\text { transformada } \\
\text { y estatus } \\
\text { demográfico } \\
\text { alto }\end{array}$ & $\begin{array}{l}\text { Actividad no } \\
\text { transformada } \\
\text { y estatus } \\
\text { demográfico } \\
\text { medio }\end{array}$ & $\begin{array}{l}\text { Actividad no } \\
\text { transformada } \\
\text { y estatus } \\
\text { demográfico } \\
\text { bajo }\end{array}$ & \\
\hline$<1000$ & 3,70 & 3,70 & 37,04 & 7,41 & 18,52 & 29,63 & 100 \\
\hline $1000-5000$ & 13,04 & 19,57 & 2,17 & 15,22 & 32,61 & 17,39 & 100 \\
\hline 5000- 10000 & 37,50 & 0,00 & 0,00 & 62,50 & 0,00 & 0,00 & 100 \\
\hline$>10000$ & 66,67 & 33,33 & 0,00 & 0,00 & 0,00 & 0,00 & 100 \\
\hline Todos & 14,29 & 13,10 & 13,10 & 16,67 & 23,81 & 19,05 & 100 \\
\hline
\end{tabular}

Fuente: IECA (Instituto de Estadística y Cartografía de Andalucía. Censo Población (2011). Estadísticas del MESS (Ministerio de Empleo y Seguridad Social). Elaboración propia. 
El interés geográfico de las categorías establecidas por la asociación de los Factores $1^{\circ}$ y $2^{\circ}$ se hace patente al considerarlas por ámbitos comarcales. En relación a ellas las comarcas presentan perfiles bastante definidos: los municipios de Antequera se concentran sobre todo en las categorías «D»y «E»; en Ronda predomina la «C» o en la Axarquía la «F». Mientras en la Costa Occidental, el 100\% de sus pocos municipios se incluyen en la "A». Solo la comarca del Guadalhorce tiene una proporción más equilibrada de casi todas ellas (Cuadro 9).

Cuadro 9. Frecuencia relativa por comarcas de cada categoría de la combinación del Factor $1^{\circ}$ y el Factor $2^{\circ}$

\begin{tabular}{|c|c|c|c|c|c|c|c|}
\hline & \multicolumn{6}{|l|}{ Categorías } & \\
\hline & $A$ & B & C & D & $E$ & $\mathrm{~F}$ & \\
\hline Comarcas & $\begin{array}{l}\text { Actividad } \\
\text { transformada } \\
\text { y estatus } \\
\text { demográfico } \\
\text { alto }\end{array}$ & $\begin{array}{l}\text { Actividad } \\
\text { transformada } \\
\text { y estatus } \\
\text { demográfico } \\
\text { medio }\end{array}$ & $\begin{array}{l}\text { Actividad } \\
\text { transformada } \\
\text { y estatus } \\
\text { demográfico } \\
\text { bajo }\end{array}$ & $\begin{array}{l}\text { Actividad no } \\
\text { transformada } \\
\text { y estatus } \\
\text { demográfico } \\
\text { alto }\end{array}$ & $\begin{array}{l}\text { Actividad no } \\
\text { transformada } \\
\text { y estatus } \\
\text { demográfico } \\
\text { medio }\end{array}$ & $\begin{array}{l}\text { Actividad no } \\
\text { transformada } \\
\text { y estatus } \\
\text { demográfico } \\
\text { bajo }\end{array}$ & \\
\hline Antequera & 4,7 & 0,0 & 0,0 & 38,1 & 42,8 & 14,2 & 100 \\
\hline Ronda & 9,0 & 9,0 & 45,4 & 0,0 & 22,7 & 13,6 & 100 \\
\hline Guadalhorce & 25,0 & 33,3 & 0,0 & 8,3 & 25,0 & 8,3 & 100 \\
\hline Axarquía & 4,5 & 18,1 & 4,5 & 18,1 & 13,6 & 40,9 & 100 \\
\hline Costa Occid & 100 & 0,0 & 0,0 & 0,0 & 0,0 & 0,0 & 100 \\
\hline $\begin{array}{l}\text { Costa } \\
\text { Oriental }\end{array}$ & 0,0 & 50,0 & 0,0 & 50,0 & 0,0 & 0,0 & 100 \\
\hline Total & 14,2 & 13,1 & 13,1 & 16,6 & 23,8 & 19,0 & 100 \\
\hline
\end{tabular}

Fuente: IECA (Instituto de Estadística y Cartografía de Andalucía. Censo Población (2011). Estadísticas del MESS (Ministerio de Empleo y Seguridad Social). Elaboración propia.

A la vista de cómo las categorías se asocian al volumen de los municipios y a las áreas geográficas, se sugiere comofactores explicativos dos circunstancias reales: la estabilidad de los pueblos que gozan de buenos recursos agrarios y la progresiva desaparición de la agricultura de algunos pequeños municipios serranos que vienen de un declive histórico.

\subsection{Combinación de los valores de los Factores $1^{\circ}$ y $3^{\circ}$}

En la misma línea, se ha procedido al análisis de la combinación de las puntuaciones del Factor $3^{\circ}$ y del Factor $1^{\circ}$. En este caso, además de perfilar los caracteres de los municipios bajo ambas variables, el resultado ha sido muy revelador del carácter complementario que tienen ambos factores para identificar la transformación productiva. Las categorías resultantes aparecen en el cuadro 10.

En todas las categorías se clasifica algún grupo de municipios. Por frecuencia, va a la cabeza con 28 de 84 municipios la categoría $2 \mathrm{~b}$, que asocia dinamismo medio-bajo y actividad no transformada, seguida de la categoría 2a que asocia dinamismo medio-bajo y actividad transformada. Ambas, que forman el conglomerado central de la clasificación,suman el 52\% de los municipios. La primera en la que se identifica el 33\% de los municipios tiene un peso significativo en todos los intervalos de tamaño inferiores a los 10000 habitantes (Cuadro 11), y destaca en dos hechos: uno, que califica al 50\% de los pueblos grandes, y otro, que es la categoría más frecuente en varias 
comarcas, especialmente en Antequera y Axarquía. La categoría 2a que le sigue, lo hace a cierta distancia: su frecuencia es bastante menor (19\% de los municipios) y también es menos generalizada pues, aunque identifica a uno de los tres municipios de más de 10000, su frecuencia se concentra entre los pequeños de $<1000$ habitantes, y por comarcas solo resulta ser la más común en la de Ronda (que a su vez es la comarca con mayor proporción de municipios de poco volumen demográfico) (Cuadro12).

Cuadro10. Categorías, población y municipios de la combinación del Factor $1^{\circ}$ y el Factor $3^{\circ}$

\begin{tabular}{|c|l|l|l|l|l|}
\hline \multicolumn{2}{|l|}{$\begin{array}{l}\text { Categorias: combinatoria Factores } 1^{\circ} \text { y } 2^{\circ} \\
N^{\circ} .\end{array}$} & \multicolumn{2}{l}{ Municipios } & \multicolumn{2}{l|}{ Población } \\
\cline { 2 - 6 } & $\%$ & Habitantes & $\%$ & \\
\hline $1^{\text {a }}$ & Alto dinamismo y actividad transformada & 7 & 8,3 & 36864 & 16,1 \\
\hline 1 b & Alto dinamismo y actividad no transformada & 10 & 11,9 & 22868 & 10,0 \\
\hline $2^{\text {a }}$ & Dinamismo medio-bajo y actividad transformada & 16 & 19,0 & 37432 & 16,4 \\
\hline $2 b$ & Dinamismo medio-bajo y actividad no transformada & 28 & 33,3 & 73591 & 32,2 \\
\hline $3^{\text {a }}$ & Dinamismo muy bajo y actividad transformada & 11 & 13,1 & 39400 & 17,3 \\
\hline $3 b$ & Dinamismo muy bajo y actividad no transformada & 12 & 14,3 & 18182 & 8,0 \\
\hline & Total & 84 & 100 & 228337 & 100 \\
\hline
\end{tabular}

Fuente: Elaboración propia.

Cuadro 11. Frecuencia relativa por tamaño de municipios de cada categoríade la combinación del Factor $1^{\circ}$ y el Factor $3^{\circ}$

\begin{tabular}{|c|c|c|c|c|c|c|c|}
\hline \multirow{2}{*}{ Población } & \multicolumn{7}{|l|}{ Categorías } \\
\hline & $1 \mathrm{a}$ & $1 b$ & $2^{a}$ & $2 b$ & $3^{a}$ & $3 b$ & \\
\hline & $\begin{array}{l}\text { Alto } \\
\text { dinamismo } \\
\text { y actividad } \\
\text { transformada }\end{array}$ & $\begin{array}{l}\text { Alto } \\
\text { dinamismo } \\
\text { con } \\
\text { actividad no } \\
\text { transformada }\end{array}$ & $\begin{array}{l}\text { Dinamismo } \\
\text { medio-bajo } \\
\text { y actividad } \\
\text { transformada }\end{array}$ & $\begin{array}{l}\text { Dinamismo } \\
\text { medio-bajo y } \\
\text { actividad no } \\
\text { transformada }\end{array}$ & $\begin{array}{l}\text { Dinamismo } \\
\text { muy bajo } \\
\text { con actividad } \\
\text { transformada }\end{array}$ & $\begin{array}{l}\text { Dinamismo } \\
\text { muy bajo con } \\
\text { actividad no } \\
\text { transformada }\end{array}$ & \\
\hline$<1000$ & 3,7 & 11,1 & 29,6 & 25,9 & 11,1 & 18,5 & 100 \\
\hline $1000-5000$ & 6,5 & 13,0 & 15,2 & 37,0 & 13,0 & 15,2 & 100 \\
\hline $5000-10000$ & 25,0 & 12,5 & 0,0 & 50,0 & 12,5 & 0,0 & 100 \\
\hline$>10000$ & 33,3 & 0,0 & 33,3 & 0,0 & 33,3 & 0,0 & 100 \\
\hline Total & 8,3 & 11,9 & 19,0 & 33,3 & 13,1 & 14,3 & 100 \\
\hline
\end{tabular}

Fuente: IECA (Instituto de Estadística y Cartografía de Andalucía. Censo Población (2011). Estadísticas del MESS (Ministerio de Empleo y Seguridad Social). Elaboración propia. 
Cuadro 12. Frecuencia relativa por comarcas de cada categoría de la combinación del Factor $1^{\circ}$ y el Factor $3^{\circ}$

\begin{tabular}{|c|c|c|c|c|c|c|c|}
\hline \multirow{3}{*}{ Comarcas } & \multicolumn{7}{|l|}{ Categorías } \\
\hline & $1 \mathrm{a}$ & $1 b$ & $2^{a}$ & $2 b$ & $3^{a}$ & $3 b$ & \\
\hline & $\begin{array}{l}\text { Alto } \\
\text { dinamismo } \\
\text { y actividad } \\
\text { transformada }\end{array}$ & $\begin{array}{l}\text { Alto dinamismo } \\
\text { con actividad no } \\
\text { transformada }\end{array}$ & $\begin{array}{l}\text { Dinamismo } \\
\text { medio-bajo } \\
\text { y actividad } \\
\text { transformada }\end{array}$ & $\begin{array}{l}\text { Dinamismo } \\
\text { medio-bajo y } \\
\text { actividad no } \\
\text { transformada }\end{array}$ & $\begin{array}{l}\text { Dinamismo } \\
\text { muy bajo } \\
\text { con actividad } \\
\text { transformada }\end{array}$ & $\begin{array}{l}\text { Dinamismo } \\
\text { muy bajo con } \\
\text { actividad no } \\
\text { transformada }\end{array}$ & \\
\hline Antequera & 0,00 & 34,78 & 4,35 & 56,52 & 0,00 & 4,35 & 100 \\
\hline Ronda & 4,55 & 4,55 & 36,36 & 13,64 & 22,73 & 18,18 & 100 \\
\hline Guadalhorce & 0,00 & 0,00 & 16,67 & 8,33 & 41,67 & 33,33 & 100 \\
\hline Axarquía & 13,64 & 13,64 & 9,09 & 45,45 & 4,55 & 13,64 & 100 \\
\hline $\begin{array}{l}\text { Costa } \\
\text { Occidental }\end{array}$ & 60,00 & 0,00 & 40,00 & 0,00 & 0,00 & 0,00 & 100 \\
\hline $\begin{array}{l}\text { Costa } \\
\text { Oriental }\end{array}$ & 0,00 & 0,00 & 50,00 & 50,00 & 0,00 & 0,00 & 100 \\
\hline Total & 8,14 & 13,95 & 18,60 & 32,56 & 12,79 & 13,95 & 100 \\
\hline
\end{tabular}

Fuente: IECA (Instituto de Estadística y Cartografía de Andalucía. Censo Población (2011). Estadísticas del MESS (Ministerio de Empleo y Seguridad Social). Elaboración propia.

La combinación que se está analizando se basa en dos factores que aportan dos dimensiones diferentes de las transformaciones socioeconómicas de los municipios. El Factor $1^{\circ}$, como se ha dicho, sobre el cambio en la estructura de las actividades, en la línea de la menor dependencia agraria y, el Factor $3^{\circ}$ sobre el dinamismo local. La lectura de ambas variables en términos de progreso, induce esperar una clara coincidencia entre ambas, de modo que las categorías «1a»y « $3 b$ » son en las que se refleja esa expectativa. Por el contrario, las categorías « $1 \mathrm{~b}$ » $\mathrm{y}$ « $3 a$ » indican exactamente una relación contraria. La realidad es que unas y otras están presentes con una frecuencia similar.

El interés de estas asociaciones es que limita el sentido de evolución/progreso de la actividad que se pudiera asignar al Factor $1^{\circ}$. En algunos casos, se desprende que la "transformación productiva» es mera consecuencia de la decadencia de las actividades locales, que por ser originariamente agrarias,se reorientan hacia actividades de servicios (a la población local, o puntuales actividades turísticas), hecho que se reconoce en municipios pequeños de montaña. Igualmente, no es regla general la coincidencia de la dependencia agraria y el bajo dinamismo local, aunque frecuentemente convergen. La idea que se quiere resaltar es que la connotación de evolución/progreso que se intuye en las puntuaciones positivas del Factor $1^{\circ}$, solo está justificada cuando se suma a puntuaciones similares del componente $3^{\circ}$.

\section{Clasificaciones derivadas del análisis factorial}

Se entiende por clasificar el proceso de determinar la clase o grupo al cual pertenece una cosa. Toda clasificación implica un proceso de generalización y por tanto de reducción de la diversidad de los individuos de la realidad a unas clases o categorías que nos van a facilitar la comprensión de dicha realidad. 
Para este análisis, el objetivo principal es diferenciar los tipos(es decir, generar una tipología) en función de la distribución de las observaciones respecto a los tres ejes o Factores, finalidad que puede lograse por dos vías metodológicas: el procedimiento directo sistemático o no, y el procedimiento estadístico, al que corresponde el método de análisis clúster.

Cada una de estas vías tiene sus propias características. El objetivo del análisis clúster es obtener grupos, llámense conglomerados o clúster, que sean lo más homogéneos posible dentro de sí mismos y diferenciados respecto a los restantes. En ese objetivo tiene que introducir alguna forma de medida de la similitud o disimilitud entre los individuos. Con mucha frecuencia se aplica la «distancia métrica» entre los individuos en relación a los valores de las variables. La condición para que esta medida sea correcta es que las coordenadas sean ortogonales (espacio euclidiano) y, está perfectamente cumplida cuando las variables son factores extraídos por el método de componentes principales.

Es una técnica exploratoria, como las clasificaciones directas, puesto que no utiliza ningún tipo de modelo estadístico para llevar a cabo el proceso de clasificación, por lo que su valor es igualmente descriptivo. El interés de este procedimiento frente a las clasificaciones directas no se basa por tanto en su capacidad explicativa o inferencial, que no la tiene, sino en descifrar la estructura real de la disposición de los casos en el espacio n-dimensional de las variables. En este sentido el resultado reproduce grupos reales entre los casos.

Respecto al modelo de clusterización, es muy usual optar cuando se trata de un número reducido de individuos por el método jerárquico aun cuando no sea muy real que exista una relación de este estilo entre los grupos. Caso contrario, el nuclear se impone siempre que el número de observaciones sea muy grande. En ambos métodos el número de grupos no está definido, de modo que es una elección a partir de los resultados.La opción adoptada responde al método aglomerativos nuclear con encadenamiento medio. Es la opción que dentro del SPSS se identificada como «Quick clúster» y K-media.

Propio de los modelos nucleares, el análisis no realiza la comparación de caso por caso, sino que parte de establecer unos centros, tantos como grupos se quieran establecer, respecto a la posición de los casos en ese espacio de n-dimensiones. Estos centros son el origen de los conglomerados. Se procede luego según reglas establecidas (en este caso K-medias) a asignar casos a cada centro hasta adjudicar todos los casos. Este proceso se repite (iteraciones) hasta obtener grupos con la menor diferencia respecto a los centros iniciales (convergencia).

El método no determina el número de grupos. La idoneidad de un número mayor o menor solo se puede desprender de la calidad de los resultados medida por su significado y por elnivel de dispersión/homogeneidad interna. Por ello se recurre normalmente a reproducir la clasificación con soluciones múltiples (es decir, para diferente número de grupos) y se comparan los resultados.

A fin de comparar los resultados se ha repetido la clasificación para las soluciones de tres, cuatro, cinco, seis, siete y ocho grupos. Se ha optado por la clasificación en 8 conglomerados. En esta decisión se ha sumado la experiencia previa del análisis de la variabilidad de las puntuaciones y los resultados de distintas clasificaciones directas, y el objetivo de obtener un número no excesivo de clases. Se han obtenido grupos bastante homogéneos que reproducen rasgos que se consideraron de interés en la inspección directa de los datos. 
El procedimiento directo permite por el contrario que el autor conduzca la clasificación de acuerdo a criterios propios. Tiene debilidades evidentes (no responder a una regla estadística objetiva, o la necesidad de manejar la información en forma de intervalos) pero da la posibilidad de generar modelos definidos por el autor de acuerdo a determinado intervalos de las variables, generalmente claros y precisos para su interpretación posterior.

\subsection{Análisis clúster}

Como resultado delanálisis clúster, tras comparar diferentes soluciones, se adoptó como más satisfactoria (por su número y por las cualidades de los clústeres) la clasificación en ocho conglomerados, cuyos tamaños van desde 6 a 20 miembros, con excepción de uno de ellos que identifica a un caso muy singular (Cuadro 13 y Figura 2).

El carácter de cada grupo se desprende del valor medio que tienen sus miembros respecto a las variables, en este caso los factores, por los que fueron clasificados. Vistos los contenidos de cada uno de ellos, se advierte que ofrecen una gradación desde las estructuras más positivas a las menos positivas, con relación a los factores que se están manejando.

En un primer nivel estaríanlos clústeres $1^{\circ}$ y $2^{\circ}$. En realidad el clúster $1^{\circ}$ es un resultado fallido pues no representa un agrupamiento sino un solo caso $^{5}$ por lo que puede asimilarse al clúster $2^{\circ}$, del que solo discrepa por rasgos más acusados. Ambos ofrecen los caracteres más favorables, con puntuaciones positivas y elevadas de los tres factores.

Representa el dinamismo de la zona litoral, con mucha actividad de servicios incluso en los que todavía mantienen la parcela de actividad agraria. Su núcleo principal lo constituye la Costa Occidental, más dos municipios en la Costa Oriental (Torrox e Instán) y otro relacionado a ella (Frigiliana). Se trata de una zona que ha experimentado un importante desarrollo turístico/residencial y la expansión de los cultivos subtropicales, aunque para sus pocos miembros no es un clúster muy homogéneo ${ }^{6}$.

En un segundo nivel dentro de esta gama de actividades transformadas sin crisis, se situaría el clúster $4^{\circ}$. Tiene altas puntuaciones en transformación productiva y en estatus demográfico. Hasta aquí muy parecido al aglomerado $1^{\circ}+2^{\circ}$. Pero les diferencia, en profundidad el Factor $3^{\circ}$, que en este clúster tiene valor muy negativo, y lo identifica de muy bajo dinamismo local. Se forma con municipios de tres comarcas: Antequera, Ronda y Guadalhorce. Es en esta última donde este agrupamiento tiene más significación, pues sus cinco municipios incluidos en el clúster son más del $40 \%$ de los existentes. Se trata, en general, de pueblos grandes para sus comarcas, productivamente transformados, casi todos con crecimientos en este siglo.

En un tercer nivel se situaría el clúster $7^{\circ}$ que representa la versión más positiva de los municipios que mantienen como actividad principal la agraria. Es un grupo que puntúa muy negativamente en transformación productiva, muy cerca de 0 en dinamismo local y con valor alto en el Factor $2^{\circ}$ de buen estatus demográfico. Compuesto por 14 municipios es el segundo en orden de tamaño

5. Su aparición no es un imprevisto pues ya se venía detectando el carácter extraordinario del caso concreto de Benahavís, con puntuación de $>7$ en el Factor $3^{\circ}$, pero en principio no se excluyó por la incertidumbre sobre si se fundiría en algún nivel determinado. Cosa que no ha ocurrido ni siquiera reduciendo a tres clústeres el conjunto de datos.

6. Descontando Benahavís, el modelo del clúster se reconoce perfectamente en la mayoría pero si fuera una clasificación supervisada habría bastantes reservas en la inclusión de Istán muy poco dinámico, e igualmente de Torrox, que se corroborará en la posterior clasificación. 
entre los ocho clústeres. Son pueblos de bases productivas agrarias que no están en crisis. No se corresponden con ningún tipo específico en cuanto a tamaños, aunque predominan los de talla mediana. Esta situación se reconoce en cuatro municipios de la Axarquía, uno en la Costa Oriental, además de nueve municipios de Antequera, lo que le convierte en el más destacado en esta comarca.

Cuadro 13. Descripción de los clústeres por los valores medios de los factores

\begin{tabular}{|c|c|c|c|c|c|}
\hline \multirow{2}{*}{ Clústeres } & \multicolumn{3}{|c|}{ Valor medio de los clúster } & \multirow{2}{*}{$\begin{array}{l}\mathrm{N}^{\circ} \text { de } \\
\text { Casos }\end{array}$} & \multirow{2}{*}{ Descripción } \\
\hline & $F^{\circ}$ & $F 3^{\circ}$ & $\mathrm{F} 2^{\circ}$ & & \\
\hline 1 & 1.41 & 7.02 & 1.15 & \multirow{2}{*}{$\begin{array}{l}1 \\
6\end{array}$} & \multirow{2}{*}{$\begin{array}{l}\text { Muy transformados productivamente, con buen estatus } \\
\text { demográfico y dinámicos }\end{array}$} \\
\hline 2 & 1.36 & 0.48 & 1.2 & & \\
\hline 4 & 0.65 & -0.82 & 0.97 & 11 & $\begin{array}{l}\text { Transformados productivamente con buen estatus } \\
\text { demográficos y sin dinamismo }\end{array}$ \\
\hline 7 & -1.07 & 0.12 & 0.9 & 14 & $\begin{array}{l}\text { Sin transformación productiva y buen estatus } \\
\text { demográfico y débil dinamismo }\end{array}$ \\
\hline 8 & -0.24 & -0.37 & -0.11 & 20 & $\begin{array}{l}\text { Sin transformación productiva, dinamismo o estatus } \\
\text { demográfico, aunque sin intensidad }\end{array}$ \\
\hline 6 & -1.07 & 0.37 & -0.77 & 13 & $\begin{array}{l}\text { Sin transformación productiva y envejecidos con ligero } \\
\text { dinamismo }\end{array}$ \\
\hline 5 & 0.54 & 0.37 & -1.39 & 12 & $\begin{array}{l}\text { Muy envejecidos con transformación productiva y ligero } \\
\text { dinamismo }\end{array}$ \\
\hline 3 & 1.48 & -0.62 & -0.39 & 7 & $\begin{array}{l}\text { Muy transformados productivamente con envejecimiento } \\
\text { y sin dinamismo }\end{array}$ \\
\hline
\end{tabular}

Fuente: IECA (Instituto de Estadística y Cartografía de Andalucía. Censo Población (2011). Estadísticas del MESS (Ministerio de Empleo y Seguridad Social). Elaboración propia.

Figura 2. Distribución de los municipios que forman los Clústeres

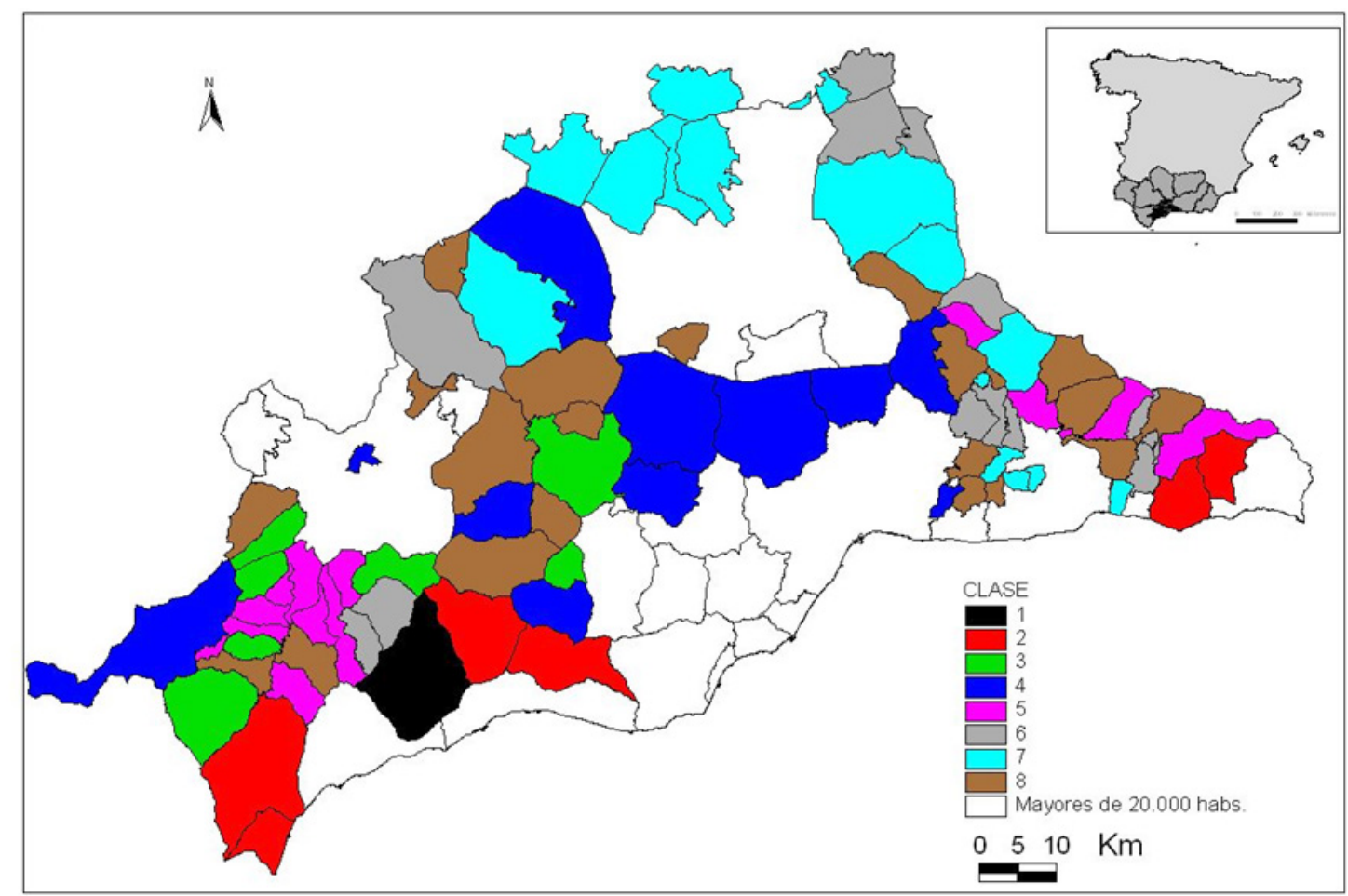

Fuente: IECA (Instituto de Estadística y Cartografía de Andalucía. Censo Población (2011). Estadísticas del MESS (Ministerio de Empleo y Seguridad Social). Elaboración propia 
Tras estos tres niveles se sitúan ya los agrupamientos con connotaciones poco positivas. Coinciden los cuatro clústeresrestantes en su estatus demográfico negativo, con o sin transformación productiva. Coinciden también en su bajo dinamismo local, aunque puede contradecirlo que algunos puntúen positivamente en el factor $3^{\circ}$, pero se reconoce en tales casos la anomalía que se señaló al comentar el factor, sobre cómo se desvirtúan sus puntuaciones en algunas poblaciones pequeñas, porque el menor paro o la atracción de ocupados, refleja carencias locales más que auténtica atracción.

Dentro de este agrupamiento con tendencias negativas, se sitúa en primer lugar el clúster $8^{\circ}$, que es el mayor de todos, con 20 municipios. Los valores de los factores, todos ellos de signo negativo, pero de poca intensidad, sitúa al agrupamiento en una estrecha banda central, sin alcanzar el nivel medio en ninguno de los tres caracteres positivos que identificaron las

Fuente: IECA (Instituto de Estadística y Cartografía de Andalucía. Censo Población (2011). Estadísticas del MESS (Ministerio de Empleo y Seguridad Social). Elaboración propia

Tras estos tres niveles se sitúan ya los agrupamientos con connotaciones poco positivas. Coinciden los cuatro clústeres restantes en su estatus demográfico negativo, con o sin transformación productiva. Coinciden también en su bajo dinamismo local, aunque puede contradecirlo que algunos puntúen positivamente en el factor $3^{\circ}$, pero se reconoce en tales casos la anomalía que se señaló al comentar el factor, sobre cómo se desvirtúan sus puntuaciones en algunas poblaciones pequeñas, porque el menor paro o la atracción de ocupados, refleja carencias locales más que auténtica atracción.

Dentro de este agrupamiento con tendencias negativas, se sitúa en primer lugar el clúster $8^{\circ}$, que es el mayor de todos, con 20 municipios. Los valores de los factores, todos ellos de signo negativo, pero de poca intensidad, sitúa al agrupamiento en una estrecha banda central, sin alcanzar el nivel medio en ninguno de los tres caracteres positivos que identificaron las nuevas variables. En definitiva, poco transformados, poco dinámicos y sin buen estatus demográfico.

Este carácter medio (objetivamente bajo) está en la base de su tamaño y de su dispersión entre muchas comarcas, salvo las dos costeras. El número mayor de miembros pertenece a la comarca de la Axarquía, pero es en los restos rurales de la comarca del Guadalhorce donde el clúster tiene más repercusión. El grupo se forma con municipios de pequeñas poblaciones que, salvo uno, todos están por debajo de los 3000 habitantes y varios por debajo de los 1000.

Le sigue, en el orden descendente el clúster $6^{\circ}$. Es un conglomerado que se caracteriza por puntuaciones muy negativas en Factor $1^{\circ}$ y Factor $2^{\circ}$, junto a una débil puntuación positiva de dinamismo local, se identifican con la otra versión de los pueblos de dependencia agraria, los ya envejecidos. Es un clúster grande formado por 13 municipios, bastante heterogéneos en cuanto a tamaño y a comarcas de pertenencia. Salvo dos miembros que pertenecen a la comarca de Ronda, el clúster se nutre de términos de la Axarquía y de Antequera, todos ellos municipios con poblaciones entre 600 y 1000 habitantes.

En el nivel inferior de esta secuencia se sitúan los agrupamientos $3^{\circ}$ y $5^{\circ}$, que reflejan situaciones de gran deterioro poblacional y productivo. En el agrupamiento $5^{\circ}$ coinciden puntuaciones positivas en transformación productiva e incluso dinamismo (ambos caracteres con moderada intensidad) con un estatus demográfico muy negativo. Agrupa 12 municipios, nueve de los cuales tienen menos de 500 habitantes y solo dos pasan de 2000 habitantes. Vistas sus puntuaciones el 
clúster $5^{\circ}$ guarda un gran parecido con el clúster $3^{\circ}$. Comparte con él el rasgo de combinar transformación productiva (en éste menos acusada) con bajo estatus demográfico (en este grupo peor) si bien difieren en el ligero dinamismo local (ligado a circunstancias puntuales) que presenta este clúster, inexistente en el grupo $3^{\circ}$.

El clúster $3^{\circ}$ es el agrupamiento que mejor refleja una asociación poco convencional de valor elevado en el Factor $1^{\circ}$ sobre «transformación productiva», y negativo en los otros dos factores: «dinamismo local» $\mathrm{y}$ «buen estatus demográfico». Recoge casosde pequeños municipios en declive muy profundo, en los que la transformación productiva está fundada en la reducción progresiva de la actividad agraria, de modo que pequeñas actividades de servicios les da el tono de transformación productiva.

Esta combinación poco convencional fue ya advertida en el análisis de la asociación entre los factores, de modo que podía intuirse que este aglomerado llegara a diferenciarse a base solo de pequeñas poblaciones. De hecho lo forman siete pequeños municipios, dos de ellos de la comarca del Guadalhorce y 5 de la comarca de Ronda.

\subsection{Clasificación supervisada no sistemática}

El objetivo principal que se plantea con esta clasificación es establecer tipos que destaquen en los fenómenos que describen los Factores, que son fenómenos positivos como la transformación productiva, el buen estatus demográfico y el dinamismo local, y para ello se recurre a establecer la clasificación a partir de las puntuaciones positivas destacadas en cada uno de ellos, tomando como umbral los valores superiores a 0,5. La clasificación con este criterio agrupa los municipios de acuerdo a los factores en los que destacan, de modo que teóricamente se pueden producir ocho grupos que son las combinaciones potenciales.

Esta clasificación no sistemática y posteriormente supervisada ha estado guiada por tres juicios de base que se han ido desprendiendo del análisis de los datos.El primer criterio de la clasificación es la estructura de la actividad: transformada o de dependencia agraria. Se basa en el buen funcionamiento de la puntuaciones positivas del Factor $1^{\circ}$, «transformación productiva» (todas salvo una ${ }^{7}$ superiores a 0,35 ) para diferenciar con bastante nitidez un grupo de individuos que pueden calificarse como de estructura económica transformada, con clara diferencia respecto al resto (puntuaciones negativas de valores muy diferentes) que podría identificarse como no transformados y de dependencia agraria. El segundo criterio es identificar las situaciones de estatus demográfico muy deteriorado, se basa en el Factor $2^{\circ}$, «buen status demográfico» quepresenta una gama de valores muy continua, pero el modelo demográfico actual (el que se desprende de las variables sobre edades, mortalidad, natalidad, etc.) no induce a calificar ni siquiera en los más elevados de ellos, un modelo de juventud explosiva, sino sencillamente una situación mejor que la del resto. Por el contrario, sus valores más negativos pueden detectar objetivamente situaciones reales de estatus demográfico muy deteriorado, es decir, de municipios demográficamente muy deprimidos. Por ello, se ha seleccionado como el segundo eje de la clasificación valores <-0,5 en el Factor $2^{\circ}$, como indicador de estatus demográfico grave que recoge aproximadamente el tercio de valores más bajos del factor. El tercer criterio se basa en identificar las situaciones que destacan en dinamismo local (Factor $3^{\circ}$ ). A diferencia del modelo demográfico, no se cuenta con una referencia que mida el significado objetivo de las puntuaciones del Factor $3^{\circ}$, fuera del contexto de este grupo de municipios, de modo que se tomaran como destacados el cuartil de mayor puntuación,

7. Cartajima, un municipio de 240 habitantes tiene puntuación positiva de 0,009. Se da incluido en el resto, es decir las negativas. 
que coincide con los valores $>0,5$, debido a la acumulación de los valores medios próximos a 0 , en el recorrido de este factor.

Con estos criterios se derivanocho combinaciones (Cuadro 14), pero se han examinado los grupos resultantes y se ha observado que dos de ellos (la combinación 5 a y la 7a) ambos con pocos individuos y generalmente de menos de 400 habitantes, ofrecen muy poco interés como grupos aislados, pues sus diferencias respecto a otras agrupaciones muy similares (la $6^{\mathrm{a}}$ y la $8^{\mathrm{a}}$, respectivamente) en todos los casos, están derivadas de los problemas ya observados en las puntuaciones del factor $3^{\circ}$ (dinamismo), cuando se trataba de entidades de población muy reducidas y envejecidas. Al refundir esas combinaciones, la clasificación queda reducida a seis tipos (Cuadro 15).

Estableciendo los grupos por la existencia de rasgos acusados cabe esperar la formación de algunos grupos más neutros o cercanos a la media. Efectivamente, el grupo mayor (clase $4^{\mathrm{a}}$ ), con más de un tercio de los municipios se identifica por la ausencia de los rasgos más acusados: «estructura de actividad no transformada, sin grave envejecimiento y sin dinamismo apreciable». Salvo en la Costa Occidental está presente en todas las comarcas, pero es en la comarca de Guadalhorce y en la de Antequera donde este tipo medio, imagen de los municipios agrarios estables y tradicionales, adquiere localmente un peso mayor. Son un tercio de los municipios del Guadalhorce y cerca del 60\% en Antequera (Cuadro 16 y Figura 3).

Cuadro 14. Combinaciones de los tres criterios y tipos de la clasificación supervisada

\begin{tabular}{|c|c|c|c|c|c|c|c|c|}
\hline \multirow{3}{*}{ 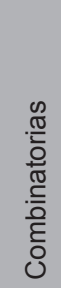 } & \multicolumn{3}{|c|}{ Criterios de clasificación } & \multirow{3}{*}{$\begin{array}{l}\text { Municipios } \\
\text { de cada } \\
\text { combina- } \\
\text { toria }\end{array}$} & \multicolumn{4}{|c|}{ CLASIFICACIÓN } \\
\hline & \multirow{2}{*}{$\begin{array}{l}\text { Estructura } \\
\text { de actividad } \\
\text { transformada }\end{array}$} & \multirow{2}{*}{$\begin{array}{l}\text { Grave } \\
\text { envejeci- } \\
\text { miento }\end{array}$} & \multirow{2}{*}{$\begin{array}{l}\text { Dinamismo } \\
\text { local } \\
\text { apreciable }\end{array}$} & & \multirow[t]{2}{*}{ TIPOS } & \multirow[t]{2}{*}{ TIPO DE LA CLASIFICACIÓN } & \multicolumn{2}{|c|}{$\begin{array}{l}\text { Municipios } \\
\text { de cada } \\
\text { tipo }\end{array}$} \\
\hline & & & & & & & $\mathrm{N}^{\circ}$ & $\%$ \\
\hline 1 & Sí & No & $\mathrm{Si}$ & 6 & $1^{\circ}$ & $\begin{array}{l}\text { Estructura de actividad } \\
\text { transformada, sin grave } \\
\text { envejecimiento y con dinamismo }\end{array}$ & 6 & 34,5 \\
\hline 2 & $\mathrm{Si}$ & No & No & 17 & $2^{\circ}$ & $\begin{array}{l}\text { Estructura de actividad } \\
\text { transformada sin grave } \\
\text { envejecimiento }\end{array}$ & 17 & 20,2 \\
\hline 3 & No & No & $\mathrm{Si}$ & 5 & $3^{\circ}$ & $\begin{array}{l}\text { Estructura de actividad } \\
\text { Estructura de actividad no } \\
\text { transformada, sin grave } \\
\text { envejecimiento y con dinamismo }\end{array}$ & 5 & 7,1 \\
\hline 4 & No & No & No & 29 & $4^{\circ}$ & $\begin{array}{l}\text { Estructura de actividad } \\
\text { Estructura de actividad no } \\
\text { transformada sin grave } \\
\text { envejecimiento }\end{array}$ & 29 & 5,9 \\
\hline 5 & No & $\mathrm{Si}$ & $\mathrm{Si}$ & 5 & $5^{\circ}$ & $\begin{array}{l}\text { Estructura de actividad } \\
\text { Estructura de actividad no } \\
\text { transformada con arave }\end{array}$ & 16 & 19,0 \\
\hline 6 & No & $\mathrm{Si}$ & No & 11 & & envejecimiento & & \\
\hline 7 & $\mathrm{Si}$ & $\mathrm{Si}$ & $\mathrm{Si}$ & 2 & $6^{\circ}$ & $\begin{array}{l}\text { Estructura de actividad } \\
\text { transformada y grave } \\
\text { envejecimiento }\end{array}$ & 11 & 13,1 \\
\hline 8 & $\mathrm{Si}$ & $\mathrm{Si}$ & No & 9 & & & & \\
\hline
\end{tabular}

Fuente: IECA (Instituto de Estadística y Cartografía de Andalucía. Censo Población (2011). Estadísticas del MESS (Ministerio de Empleo y Seguridad Social). Elaboración propia. 
Cuadro 15. Tipología de la clasificación supervisada y proporción de municipios por comarcas

\begin{tabular}{|c|c|c|c|c|c|c|c|c|}
\hline & $\begin{array}{l}\text { Tipos de la } \\
\text { clasificación } \\
\text { supervisada }\end{array}$ & Antequera & Ronda & Guadalhorce & Axarquía & Costa Occ. & Costa Or. & Total \\
\hline 1 & $\begin{array}{l}\text { Estructura } \\
\text { de actividad } \\
\text { transformada, } \\
\text { sin grave } \\
\text { envejecimiento, } \\
\text { con dinamismo }\end{array}$ & 0,0 & 0,0 & 0,0 & 9,09 & 80,0 & 0,0 & 7,1 \\
\hline 2 & $\begin{array}{l}\text { Estructura } \\
\text { de actividad } \\
\text { transformada } \\
\text { sin grave } \\
\text { envejecimiento, } \\
\text { sin dinamismo }\end{array}$ & 4,8 & 18,18 & 58,3 & 13,6 & 20,0 & 50.0 & 20,2 \\
\hline 3 & $\begin{array}{l}\text { Estructura de } \\
\text { actividad no } \\
\text { transformada, } \\
\text { sin grave } \\
\text { envejecimiento, } \\
\text { con dinamismo }\end{array}$ & 23,8 & 0,0 & 0,0 & 0,0 & 0,0 & 0,0 & 5,95 \\
\hline 4 & $\begin{array}{l}\text { Estructura de } \\
\text { actividad no } \\
\text { transformada } \\
\text { sin grave } \\
\text { envejecimiento, } \\
\text { con dinamismo }\end{array}$ & 57,1 & 22,3 & 33,3 & 31,8 & 0,00 & 50 & 34,5 \\
\hline 5 & $\begin{array}{l}\text { Estructura de } \\
\text { actividad no } \\
\text { transformada, } \\
\text { grave } \\
\text { envejecimiento }\end{array}$ & 14,3 & 13,64 & 8,33 & 40,9 & 0,00 & 0 & 19,0 \\
\hline 6 & $\begin{array}{l}\text { Estructura } \\
\text { de actividad } \\
\text { transformada, } \\
\text { grave } \\
\text { envejecimiento }\end{array}$ & 0,0 & 45,45 & 0,00 & 4,55 & 0,00 & 0 & 13,1 \\
\hline & & 100 & 100 & 100 & 100 & 100 & 100 & 100 \\
\hline
\end{tabular}

Fuente: IECA (Instituto de Estadística y Cartografía de Andalucía. Censo Población (2011). Estadísticas del MESS (Ministerio de Empleo y Seguridad Social). Elaboración propia.

El segundo lugar en volumen de clasificados está el Tipo 2, aunque sin similar dependencia agraria. Este Tipo se definiría «con estructura de actividad transformada sin grave envejecimiento y dinamismo» e identifica un $20 \%$ de los municipios. Está presente en todas las comarcas, y en la del Guadalhorce es el tipo dominante. No se vinculan a unasdimensionesprecisas, si bien son pueblos medios (solo dos tienen unos 700 habitantes) o grandes, como los dos mayores de la comarca del Guadalhorce, Pizarra y Alora con 9073 y 12924 habitantes respectivamente y Torrox (15371 habitantes) de la Costa Oriental. Entre ambos grupos reúnen el 54\% de los municipios, que no despuntan ni por un envejecimiento grave ni por un dinamismo local apreciable.

Solo dos tipos de la clasificación comparten un valor destacado en dinamismo local, en ambos se identifican un número reducido de individuos y comparten no coincidir con envejecimiento grave. Uno de ellos es el Tipo $1^{\circ}$ que ocuparía el primer lugar en una jerarquía bajo estos conceptos: "con estructura de actividad transformada, sin grave envejecimiento y con dinamismo», engloba 6 municipios, entre la Costa occidental, que se vinculan entre sí bajo cualquier clasificación, y la Axarquía. El otro con un valor destacado en dinamismo local es también minoritario. Se trata del 
Tipo $3^{\circ}$ que seidentifica «con estructura de actividad no transformada, sin grave envejecimiento y con dinamismo». Solo engloba cinco municipios, y todos son pequeños pueblos de Antequera, habría que indagar si coincide con alguna experiencia de desarrollo local, o sencillamente con el cultivo del olivar.

Cuadro 16.Valores medios de la clasificación supervisada

\begin{tabular}{|l|l|l|l|l|l|}
\hline \multirow{2}{*}{ Clases } & \multirow{2}{*}{$\begin{array}{l}\mathrm{N}^{\circ} \\
\text { Casos }\end{array}$} & \multirow{2}{*}{ Tipos de la supervisada } & \multicolumn{2}{|l|}{ Valor medio } \\
\cline { 5 - 7 } & & & F. $1^{\circ}$ & F. $2^{\circ}$ & F. $3^{\circ}$ \\
\hline 1 & 6 & $\begin{array}{l}\text { Estructura de actividad transformada, sin } \\
\text { grave envejecimiento, con dinamismo }\end{array}$ & 1,22 & 1,15 & 1,82 \\
\hline 2 & 17 & $\begin{array}{l}\text { Estructura de actividad transformada sin } \\
\text { grave envejecimiento, sin dinamismo }\end{array}$ & 0,97 & 0,52 & $-0,58$ \\
\hline 3 & 5 & $\begin{array}{l}\text { Estructura de actividad no transformada, } \\
\text { sin grave envejecimiento, con dinamismo }\end{array}$ & $-1,05$ & 0,33 & 0,68 \\
\hline 4 & 29 & $\begin{array}{l}\text { Estructura de actividad no transformada sin } \\
\text { grave envejecimiento, dinamismo }\end{array}$ & $-0,64$ & 0,43 & $-0,23$ \\
\hline 5 & 16 & $\begin{array}{l}\text { Estructura de actividad no transformada } \\
\text { con grave envejecimientos }\end{array}$ & $-0,68$ & $-0,95$ & 0,15 \\
\hline 6 & 11 & $\begin{array}{l}\text { Estructura de actividad transformada, con } \\
\text { grave envejecimientos }\end{array}$ & 0,98 & $-1,33$ & $-0,01$ \\
\hline
\end{tabular}

Fuente: IECA (Instituto de Estadística y Cartografía de Andalucía. Censo Población (2011). Estadísticas del MESS (Ministerio de Empleo y Seguridad Social). Elaboración propia.

Figura 3: Municipios que integran la clasificación supervisada

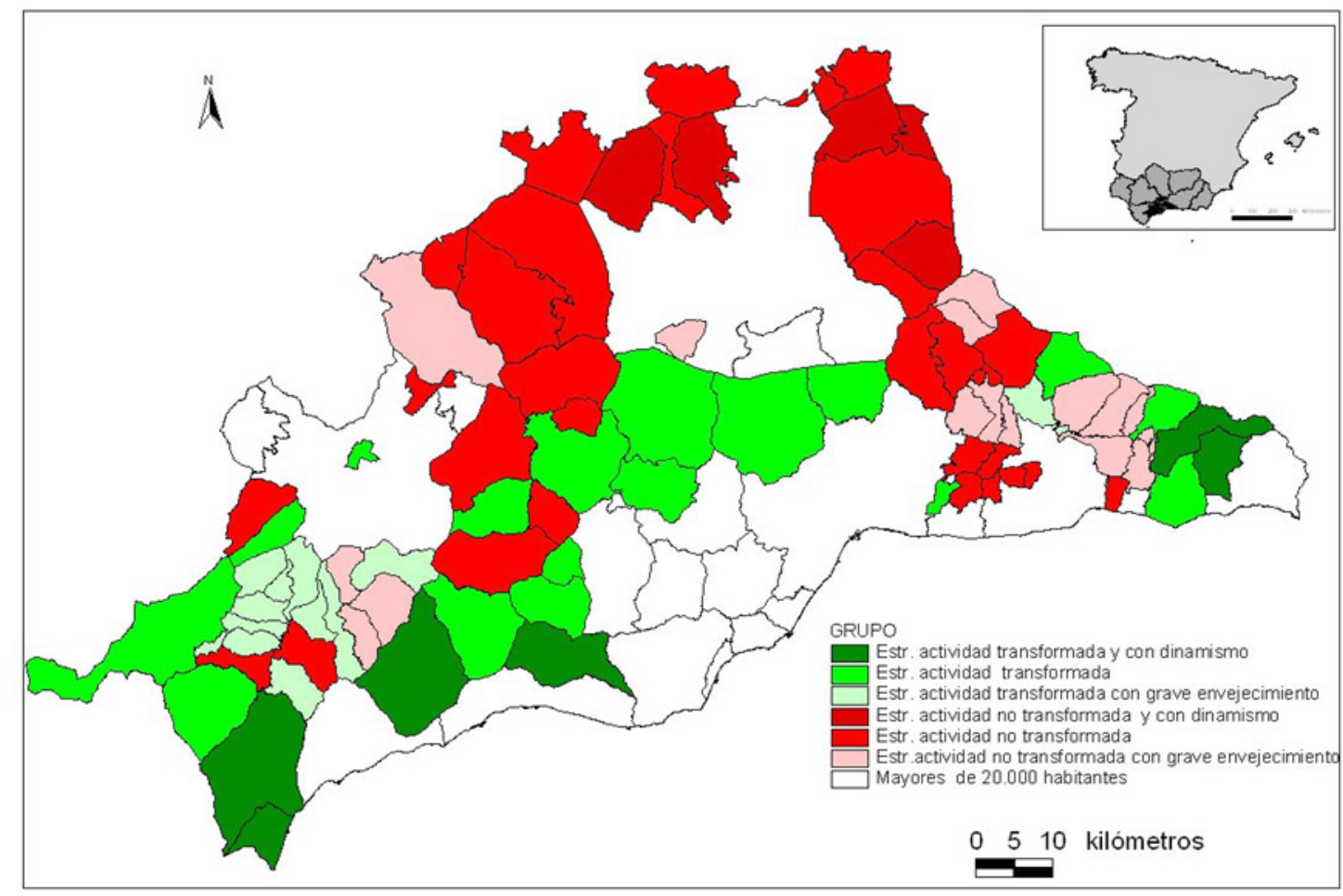

Fuente: IECA (Instituto de Estadística y Cartografía de Andalucía. Censo Población (2011). Estadísticas del MESS (Ministerio de Empleo y Seguridad Social). Elaboración propia 
La clasificación concentra en dos tipos los espacios rurales con graves problemas en su estatus demográfico (que se corresponden con el cuartil de peor puntuación en el factor $2^{\circ}$ ), y como en ninguno de ellos el Factor $3^{\circ}$ tiene una gran significación, la diferencia entre ellos radica en su dependencia agraria o en su estructura de actividad transformada (son los Tipos $5^{\circ}$ y $6^{\circ}$ ).

El Tipo $5^{\circ}$ "con estructura productiva no transformada y grave envejecimiento» es uno de los más numerosos (el tercero en ese ranking), engloba 16 municipios con presencia en varias comarcas no costeras, pero con una presencia especial en la comarca de la Axarquía donde identifica al 40\% de los municipios. Mientras el Tipo $6^{\circ}$, aúna «estructura de actividad transformada y grave envejecimiento» identifica municipios de menos de 1000 habitantes y es esencialmente rondeño (la comarca afinca ocho de los nueve clasificados) y define más del $45 \%$ de sus términos municipales.

Estos dos tipos que abarcan los términos municipales más deteriorados demográficamente, tienen una coherencia plena con los caracteres de las áreas geográficas en que se localizan, pues ambos denotan la crisis de los pequeños términos de montaña en las comarcas de la Axarquía y de Ronda, siendo la diferencia entre ellos el papel a que ha quedado reducida en la montaña la agricultura como actividad inductora tradicional, lo que refleja la mayor gravedad de este proceso en la de Ronda que en la Axarquía.

\subsection{Comparación de la clasificación supervisada con el análisis clúster}

Hay pocas expectativas de coincidencia entre estas clasificaciones, que difieren en su fundamento metodológico (directa frente a estadística), y en el marcado carácter subjetivo por el que se diferencian sus clases.

A pesar de ello se ha mantenido el mismo criterio de comparación, estableciendo los valores medios del grupo, a fin de compararlos con los valores medios de los clústeres.

La menor homogeneidad intragrupos de la supervisada era de esperar. Es natural que aumente la heterogeneidad interna si el mismo universo se divide en un número menor de clases. Por otra parte, los criterios estrictos de la supervisada para destacar el grave envejecimiento o el dinamismo local apreciable, deja un amplio margen para los valores de las puntuaciones de los Factores $2^{\circ}$ y $3^{\circ}$ que se engloban en los tipos que no destacan en ellos.

Fuente: IECA (Instituto de Estadística y Cartografía de Andalucía. Censo Población (2011). Estadísticas del MESS (Ministerio de Empleo y Seguridad Social). Elaboración propia

\subsection{Comparación de la clasificación supervisada con el análisis clúster}

Hay pocas expectativas de coincidencia entre estas clasificaciones, que difieren en su fundamento metodológico (directa frente a estadística), y en el marcado carácter subjetivo por el que se diferencian sus clases.

A pesar de ello se ha mantenido el mismo criterio de comparación, estableciendo los valores medios del grupo, a fin de compararlos con los valores medios de los clústeres. La menor homogeneidad intragrupos de la supervisada era de esperar. Es natural que aumente la heterogeneidad interna si el mismo universo se divide en un número menor de clases. Por otra parte, los criterios estrictos de la supervisada para destacar el grave envejecimiento o el dinamismo local apreciable, 
deja un amplio margen para los valores de las puntuaciones de los Factores $2^{\circ}$ y $3^{\circ}$ que se engloban en los tipos que no destacan en ellos.

Por ello es razonable reducir la comparación a comprobar la forma en que se superponen sus clases para advertir sus espacios de coincidencia si efectivamente existen (Figura 4). ${ }^{8}$ Efectivamente se aprecia que existen algunos espacios de coincidencias, pero la nota más destacadas esque ningún miembro de los clústeresse identifica totalmente con los de una clase de la supervisada y, por tanto, cada clase de ésta se forma a partir de individuos de varios clústeres:la clase 4 se forma a partir de individuos de 3 clústeres $\left(6^{\circ}, 8^{\circ}, 7^{\circ}\right)$, la clase 2 con los clústeres $3^{\circ}, 2^{\circ}$ y $4^{\circ}$; la clase 4 con los miembros de los clústeres, $8^{\circ}, 7^{\circ}, 6^{\circ}, 3^{\circ}$, etc.).

Figura 4: Comparación entre las clasificaciones Clúster y Supervisada

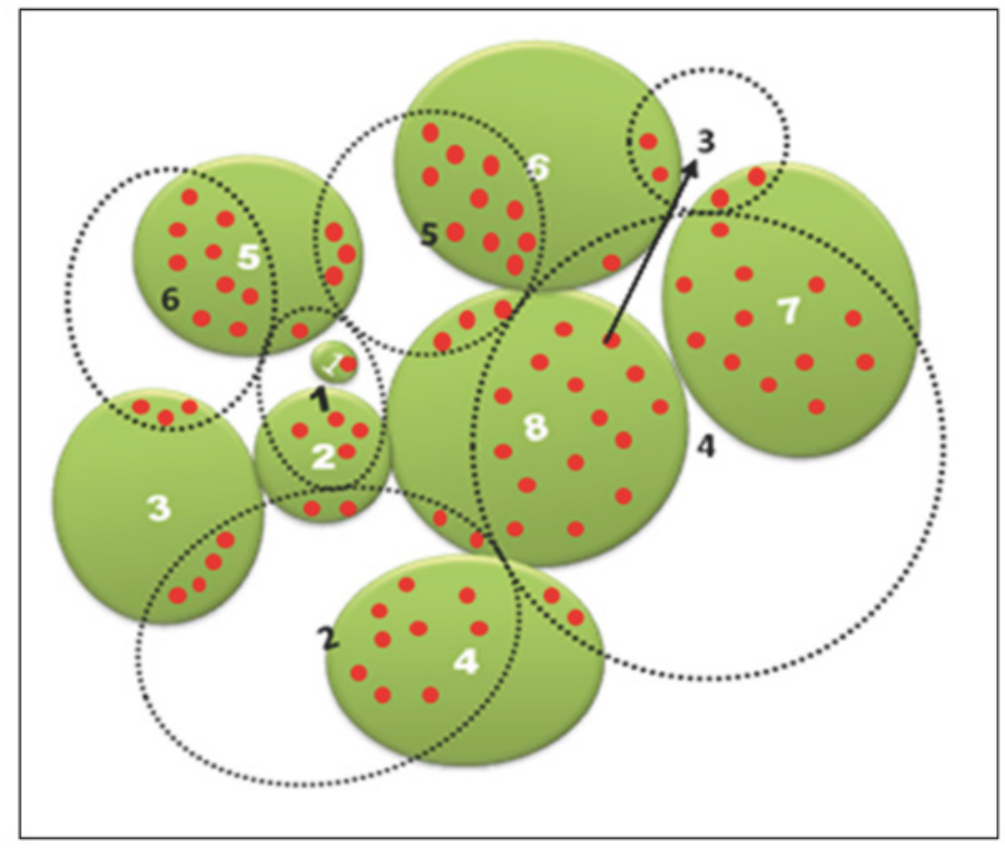

Aros negros, cada tipo de la clasificación supervisada

Círculos verdes, cada uno de los clústeres -Un municipio Fuente: Elaboración propia.

De los 8 clústeres proporcionados por el análisis de conglomerados, seis ven como sus municipios presentan una actividad transformada no agraria (del uno al sexto), mientras queen la clasificación supervisada, dicha transformación define a los miembros de tres clases: la 1,2 y 6.

Si analizamos al factor buen estatus demográfico, su carácter positivo define a los individuos de los clústeres $1^{\circ}, 2^{\circ}, 4^{\circ}, 7^{\circ}$ y $8^{\circ}$ (aunque el último con un sesgo ligero), hecho que se repite en las clases 3,5 y 6 de la directa.

Respecto al factor dinamismo de sus economías, en la clasificación estadística, el único clúster cuyos municipios no lo registran es el número $3^{\circ}$, siendo en $\operatorname{los} 1^{\circ}$ y $2^{\circ}$ donde el nivel es más fuerte y en los restantes cinco sólo puede considerarse moderado. Mientras que en la clasificación supervisada presentan dinamismo las clases 1,3 y 5 .

8. La flecha sobrepuesta al gráfico quiere dar cuenta de que uno de los individuos del clúster ocho está comprendido en la clase tres, aunque su círculo no lo abarque. Esta es una solución de compromiso por la dificultad de situar dentro del diagrama a la clase 3, que comparte miembros con los clústeres 6,7 y 8, pero al mismo tiempo ha de ser disjunta respecto a la clase $4^{\circ}$. 
Esta falta de coherencia se puede corroborar en el cuadro 17 que recoge un ejercicio de identificación de los individuos de los clústeres con los tipos de la clasificación supervisada. Las clases 1 de la clasificación supervisada y los clústeres $1^{\circ}$ y $2^{\circ}$ son los agrupamientos que tienen más coincidencia, aunque la supervisada incorpora un municipio más, Cómpeta, por su mayor nivel de envejecimiento, y deja fuera a Istán y Torrox por su menor dinamismo respecto a los otros términos, algo que ya se advirtió en el análisis clúster. Esta clase es la que ofrece los rasgos más positivos en los tres factores, y su localización es precisa, el litoral occidental (5 municipios) y dos pueblos de la Axarquía: Frigiliana y el costero de Torrox.

Otra importante aproximación se establece entre la clase 2 de la supervisada y el clúster $4^{\circ}$ (sus caracteres serían transformación productiva, buen estatus demográfico y débil/sin dinamismo). Esta clase 2 suma 17 municipios, siendo predominantes los de la comarca del Guadalhorce (6 municipios) y Ronda (5 municipios) y los tamaños medio/grandes, aunque también reúne localidades de la Axarquía (4, uno de ellos costero, Torrox) y de la comarca norte (Casabermeja) y litoral occidental (Istán).

Las clases 3 y 4 de la supervisada (la diferencia entre ellas es la existencia o no de dinamismo, y ambas presentan rasgos de economía tradicional y menor envejecimiento) tienen cierta similitud con los clústeres $7^{\circ}$ y $8^{\circ}$ (los únicos que se definen por su no transformación productiva y relativo buen estatus demográfico). El espacio de mayor concentración de los municipios de la clase 3 (5 municipios) es la Depresión de Antequera, mientras que los de la clase 4, que con 29 municipios es el grupo de mayor número de individuos, se reparten mayoritariamente entre las comarcas de Antequera y la Axarquía (respectivamente con 11 y 10 términos), aunque también hay en ella términos de la comarca del Guadalhorce (4 municipios)y tres de la rondeña. Se trata de 34 municipios que mantienen su caracterización agraria,perolos de la 3 conocen cierto dinamismo, mientras que los de la abultada clase 4 no.

El siguiente agrupamiento de la supervisada, la clase 5, comparte un importante grado de similitud con el clúster $6^{\circ}$, debido al envejecimiento y dinamismo local de sus municipios, aunque el tipo de evolución de la actividad es dual y por tanto une términos tanto de actividad transformada como tradicional agraria. La Axarquía es la comarca de donde procede la fracción más importante de sus miembros (11 de 16).

Por último, indicar que la clase 6 tiene muchos paralelismos con los clústeres $3^{\circ}$ y $5^{\circ}$ (la transformación de la economía, el envejecimiento y la falta o levedad de dinamismo económico). Desde el punto de vista territorial señalar que todos los términos que se incluyen en esta clase a excepción de un municipio de la Axarquía (La Viñuela), son 10 pequeños municipios de montaña (Comarca de Ronda). 
Cuadro 17. Identificación de los miembros de cada clúster con las clases de la clasificación supervisada

\begin{tabular}{|c|c|c|c|c|c|c|c|}
\hline \multirow{2}{*}{ 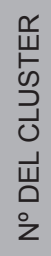 } & \multirow[b]{2}{*}{$\begin{array}{l}\text { DESCRIPCIÓN } \\
\text { DEL CLUSTER }\end{array}$} & Clase 1 & Clase 2 & Clase 3 & Clase 4 & Clase 5 & Clase 6 \\
\hline & & $\begin{array}{l}\text { E. Ac. } \\
\text { transformada, } \\
\text { sin grave env., } \\
\text { con dinamismo }\end{array}$ & $\begin{array}{l}\text { E. Ac. } \\
\text { transformada } \\
\text { sin grave env., } \\
\text { sin dinamismo. }\end{array}$ & $\begin{array}{l}\text { E. Ac. no } \\
\text { transformada, sin } \\
\text { grave env. y con } \\
\text { dinamismo }\end{array}$ & $\begin{array}{l}\text { E. Ac. no } \\
\text { transformada } \\
\text { sin grave env, } \\
\text { sin dinamismo }\end{array}$ & $\begin{array}{l}\text { E. Ac. No } \\
\text { transformada } \\
\text { con grave } \\
\text { env., con } \\
\text { dinamismo }\end{array}$ & $\begin{array}{l}\text { E. Ac. } \\
\text { transformada } \\
\text { y con grave } \\
\text { env., sin } \\
\text { dinamismo }\end{array}$ \\
\hline 1 & \multirow{5}{*}{$\begin{array}{l}\text { Estructura de } \\
\text { actividad muy } \\
\text { transformada, } \\
\text { con buen estatus } \\
\text { demográfico y } \\
\text { dinámicos }\end{array}$} & Benahavís & & & & & \\
\hline \multirow[t]{4}{*}{2} & & Casares & Istán & & & & \\
\hline & & Frigiliana & Torrox & & & & \\
\hline & & Manilva & & & & & \\
\hline & & Ojén & & & & & \\
\hline \multirow[t]{4}{*}{3} & \multirow{4}{*}{$\begin{array}{l}\text { Estructura de } \\
\text { actividad muy } \\
\text { transformada } \\
\text { con estatus } \\
\text { demográfico } \\
\text { negativo y sin } \\
\text { dinamismo }\end{array}$} & & Benaoján & & & & Algatocín \\
\hline & & & Casarabonela & & & & $\begin{array}{l}\text { Jimera de } \\
\text { Líbar }\end{array}$ \\
\hline & & & Gaucín & & & & Parauta \\
\hline & & & Guaro & & & & \\
\hline \multirow[t]{9}{*}{4} & \multirow{9}{*}{$\begin{array}{l}\text { Estructura } \\
\text { de actividad } \\
\text { transformada } \\
\text { con buen estatus } \\
\text { demográfico, } \\
\text { débil dinamismo }\end{array}$} & & Almogía & & Campillos & & \\
\hline & & & Álora & & Colmenar & & \\
\hline & & & Arriate & & & & \\
\hline & & & Casabermeja & & & & \\
\hline & & & $\begin{array}{l}\text { Cortes de la } \\
\text { Frontera }\end{array}$ & & & & \\
\hline & & & Monda & & & & \\
\hline & & & Pizarra & & & & \\
\hline & & & Totalán & & & & \\
\hline & & & Yunquera & & & & \\
\hline \multirow[t]{8}{*}{5} & \multirow{8}{*}{$\begin{array}{l}\text { Estatus } \\
\text { demográfico } \\
\text { muy negativo } \\
\text { con estructura } \\
\text { de actividad } \\
\text { transformada y } \\
\text { ligero dinamismo }\end{array}$} & Cómpeta & & & & Alfarnatejo & Alpandeire \\
\hline & & & & & & Cartajima & Atajate \\
\hline & & & & & & Sedella & Benadalid \\
\hline & & & & & & & Benalauría \\
\hline & & & & & & & Faraján \\
\hline & & & & & & & Genalguacil \\
\hline & & & & & & & Júzcar \\
\hline & & & & & & & Viñuela \\
\hline \multirow[t]{10}{*}{6} & \multirow{10}{*}{$\begin{array}{l}\text { Estructura } \\
\text { de actividad } \\
\text { transformada, } \\
\text { estatus } \\
\text { demográfico } \\
\text { negativo con } \\
\text { ligero dinamismo }\end{array}$} & & & V. de Algaidas & $\begin{array}{l}\text { Cuevas del } \\
\text { Becerro. }\end{array}$ & Alfarnate & \\
\hline & & & & V. del Trabuco & & Árchez & \\
\hline & & & & & & Benamargosa & \\
\hline & & & & & & $\begin{array}{l}\text { Cañete la } \\
\text { Real }\end{array}$ & \\
\hline & & & & & & Comares & \\
\hline & & & & & & Cútar & \\
\hline & & & & & & Igualeja & \\
\hline & & & & & & Pujerra & \\
\hline & & & & & & Salares & \\
\hline & & & & & & Sayalonga & \\
\hline
\end{tabular}




\begin{tabular}{|c|c|c|c|c|c|c|c|}
\hline \multirow{2}{*}{ 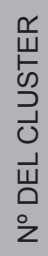 } & \multirow[b]{2}{*}{$\begin{array}{l}\text { DESCRIPCIÓN } \\
\text { DEL CLUSTER }\end{array}$} & Clase 1 & Clase 2 & Clase 3 & Clase 4 & Clase 5 & Clase 6 \\
\hline & & $\begin{array}{l}\text { E. Ac. } \\
\text { transformada, } \\
\text { sin grave env., } \\
\text { con dinamismo }\end{array}$ & $\begin{array}{l}\text { E. Ac. } \\
\text { transformada } \\
\text { sin grave env., } \\
\text { sin dinamismo. }\end{array}$ & $\begin{array}{l}\text { E. Ac. no } \\
\text { transformada, sin } \\
\text { grave env. y con } \\
\text { dinamismo }\end{array}$ & $\begin{array}{l}\text { E. Ac. no } \\
\text { transformada } \\
\text { sin grave env, } \\
\text { sin dinamismo }\end{array}$ & $\begin{array}{l}\text { E. Ac. No } \\
\text { transformada } \\
\text { con grave } \\
\text { env., con } \\
\text { dinamismo }\end{array}$ & $\begin{array}{l}\text { E. Ac. } \\
\text { transformada } \\
\text { y con grave } \\
\text { env., sin } \\
\text { dinamismo }\end{array}$ \\
\hline \multirow[t]{12}{*}{7} & \multirow{12}{*}{$\begin{array}{l}\text { Estructura de } \\
\text { actividad no } \\
\text { transformada, } \\
\text { buen estatus } \\
\text { demográfico, } \\
\text { ligero dinamismo }\end{array}$} & & & Fuente de Piedra & Alameda & & \\
\hline & & & & Mollina & Algarrobo & & \\
\hline & & & & & Almáchar & & \\
\hline & & & & & Archidona & & \\
\hline & & & & & Benamocarra & & \\
\hline & & & & & Cuevas Bajas & & \\
\hline & & & & & Humilladero & & \\
\hline & & & & & Iznate & & \\
\hline & & & & & Periana & & \\
\hline & & & & & $\begin{array}{l}\text { Sierra de } \\
\text { Yeguas }\end{array}$ & & \\
\hline & & & & & Teba & & \\
\hline & & & & & V. del Rosario & & \\
\hline \multirow[t]{14}{*}{8} & \multirow{14}{*}{$\begin{array}{l}\text { Medio bajo en } \\
\text { transformación } \\
\text { de estructura } \\
\text { de actividad, } \\
\text { dinamismo } \\
\text { o estatus } \\
\text { demográfico. }\end{array}$} & & Alcaucín & V. de Tapia & Almargen & Arenas & \\
\hline & & & $\begin{array}{l}\text { Canillas de } \\
\text { Albaida. }\end{array}$ & & Alozaina & $\begin{array}{l}\text { Canillas de } \\
\text { Aceituno. }\end{array}$ & \\
\hline & & & & & Ardales & $\begin{array}{l}\text { Valle de } \\
\text { Abdalajís }\end{array}$ & \\
\hline & & & & & Benarrabá & & \\
\hline & & & & & Borge (El) & & \\
\hline & & & & & Burgo (El) & & \\
\hline & & & & & Carratraca & & \\
\hline & & & & & $\begin{array}{l}\text { Cuevas de } \\
\text { San M. }\end{array}$ & & \\
\hline & & & & & Jubrique & & \\
\hline & & & & & Macharaviaya & & \\
\hline & & & & & Moclinejo & & \\
\hline & & & & & Montejaque & & \\
\hline & & & & & Riogordo & & \\
\hline & & & & & Tolox & & \\
\hline
\end{tabular}

Fuente: IECA (Instituto de Estadística y Cartografía de Andalucía. Censo Población (2011). Estadísticas del MESS (Ministerio de Empleo y Seguridad Social). Elaboración propia.

\section{Conclusiones}

La delimitación del ámbito rural bien desde una perspectiva científico-académica u operativa ha sido un tema ampliamente debatido. Los intentos por delimitar este espacio han sido múltiples desde mediado del S. XX y, pese a ello, hoy en día no existe una definición comúnmente aceptada entre la comunidad científica, lo que evidencia la complejidad de este proceso.

La ruralidad, por su diversificación, gradación ypor su conceptualización multidimensional, difícilmente puede ser abordable desde una única perspectiva (Larrubia, 1998), sino que su deli- 
mitación y análisis necesita de unos enfoques y variables que atiendan la especificidad de cada contexto temporal y territorial. Los criterios demográficos, aunque sean los más fáciles de determinar y los más extendidos, no son suficientes, es necesario diseñar indicadores que tengan en cuenta aspectos o dimensiones de carácter social, cultural y económicos (multidimensionales) que permitan comprender la realidad de los espacios rurales.

La aportación que en este sentido supone este trabajonos permite realizar varias conclusiones.

La primera, de carácter general, esconfirmar la adecuación de la metodología utilizada para aprehender la diversidad del espacio rural a escala provincial, y la segunda, en el plano metodológico, subrayar la necesidad de conocery contar con un número amplio de variables que cubran variados aspectos o temáticas de interés en el espacio rural, y la importancia de realizar una apropiada selección de las mismas, como fase inicial para averiguar mediante el análisis factorial los factores subyacentes que explican la realidad que se estudia. Unos ejes que tras su identificación podremos utilizar para realizar una tipificación de base estadística.

La tercera es la utilidad que posee en el análisis geográfico la sistematización de la información y la generación de modelos o tipologías. Sin necesidad de decantarse por una de ella, su utilidad no es un tema discutido. Cabe plantear, sin embargo, el valor que tienen sus resultados. Una misma población con sus caracteres específicos puede encasillarse en diferentes conjuntos de clases, según los criterios de clasificación que se adopten aún dentro de una misma metodología. Y es evidente quesi no existe una solución única, deben sopesarse los criterios de clasificación y evaluar el significado de los resultados que se desprendan.

En cuanto a los resultados concretos confirmar la existencia de niveles o grados de ruralidad en el espacio rural malagueño que se definirían por los distintos clústeres o clases obtenidas mediante las clasificaciones estadística y supervisada. Agrupamientos de municipios con caracteres diferentes atendiendo a la existencia actual de tres fenómenos: la transformación productiva, el envejecimiento y el dinamismo económico, y que se han obtenido mediante dos diferenciados procedimientos de clasificación, pero que en ambas soluciones ofrecen una comprensión y ligazón territorial claras. Circunstancia que vuelve a confirmar que la clave del éxito en este tipo de procesos se sitúa en el trabajo realizado con las variables.

Respecto al concepto de ruralidad y especialmente a la aceptación de sus vinculaciones a lo agrario, los resultados de este trabajo inducen al replanteamiento del concepto rural profundo ligado a una exclusiva dependencia de unas actividades agrarias en decadencia. Los resultados obtenidos muestran que puede manifestarse en sentido contrario, es decir, con una transformación de la actividad productiva que los identifica de poca dependencia agraria, como resultado de la propia decadencia económica y demográfica local. Reflexión que abre el camino a la necesidad de prestar más atención en el ámbito local a temas relativos a ingresos no productivos y,ayudas sociales que pudieran explicar el funcionamiento y mantenimiento de comunidades no agrarias en el espacio rural, y de forma paralela la importancia de estudiar las fuentes estadísticas que puedan adoptarse para su inclusión en este tipo de análisis cuantitativo.

Los contrastes que se han observado respecto a los reconocidos unas décadas atrás, podrían inducir a considerar si en términos generales, el motor son hoy procesos de tipo endógeno, frente a la irradiación urbana de décadas anteriores, o bien se trata de una adaptación peculiar de las actividades clásicamente urbanas en espacios rurales. Esta importante apreciación queda pendiente de comprobación, cuando se amplíe el análisis a otras provincias. 


\section{Agradecimientos}

Queremos expresar y reconocer la gran oportunidad que ha supuesto para las autoras de este trabajo el haber contado con las enseñanzas y la guía de la doctora Ocaña Ocaña, M.C. en su fructífera trayectoria universitaria en Málaga. Estaremos siempre infinitamente agradecidas por su labor docente y de investigación que nos abrió el camino hacia nuestro presente profesional, pero sobre todo queremos mostrar nuestra gratitud por la humanidad y generosidad de la que ha hecho gala siempre a lo largo de nuestro camino en común, y que también se ha convertido para nosotras en un referente. Una gratitud que debemos extender a su acertada orientación y crítica en la elaboración de este trabajo.

\section{Bibliografía}

- Armas-Quinta, F.X., Macía-Arce, F.X. (2017). Reflexiones acerca de la delimitación y definición del medio rural. Diseño de un índice de ruralidad para Galicia. Finisterra, LII, 106, 85 -101. doi: https://doi.org/10.18055/Finis9955

- Ballas, D., Kalogeresis,T.,\& Labrianidis,L., (2003). «A comparative study of typologies for rural áreas in Europa». 43 Edictión European Congress of the Regional Science Association. Jyväskylä, Finland, 27-30 august 2003. Recuperado de /Retrieved fromhttps://www.jyu.fi/ersa2003/cdrom/papers/515.pdf

- Brezzi, M.L.,Dijkstra, \& Ruiz, V. (2011). OECD Extended Regional Typology. The economic performance of remote rural regions.Documento de trabajo OECD Regional Development Working Papers 2011/06. Recuperado de / Retrieved from http://www.oecd.org/cfe/regional-policy/48670214.pdf .

- Camarero. L. A. (Coord.) (2009). La población rural de España. De los desequilibrios a la sostenibilidad social. Colección Estudios, 37. Barcelona: Fundación La Caixa.

- Cloke, P.J. (1977). Anindez of ruralityforEngland and Wales. Regional Studies, 11, 143-152. Doi: https://doi. org/10.1080/09595237700185041

- Clout, H. (1993).European exprerience of rural development. London: Rural Development Commission.

- ComisiónEuropea (1999). Sexto informe sobre las Regiones.Recuperado de/ Retrieved from https://ec.europa.eu/ regional_policy/sources/docoffic/official/reports/cohesion6/6cr_es.pdf.

- Echeverri-Perico, R. Echeverri, A.M. (2012). Marco analítico para abordar el concepto rural. Análisis realizado por Proterritorios en el marco del Estudio sobre Concepciones Contemporáneas de Ruralidad auspiciado por el Instituto Interamericano de Cooperación para la Agricultura, IICA, Brasil. Recuperado de /Retrieved From http:// www.proterritorios.net/site_v14/index.php?page=view\&id=pro154894

- Entrena-Durán, F. (1998): Cambios en la construcción social de lo rural. De la autarquía a la globalización. Tecnos, Madrid.

- Esparcia, J. (2012). Evolución reciente, situación actual y perspectivas futuras en el desarrollo rural en España y en la UE. RevueMarocained'AdministrationLocale et de Développement, 79, 53-84. Recuperado de /Retrieved from https://es.scribd.com/document/317227642/Esparcia-Des-Rural-Perspectiva-Historia-y-de-Futuro-2012-pdf

- EUROSTAT (2011). Urban-rural tipology. Recuperado de/Retroived from https://ec.europa.eu/eurostat/statisticsexplained/index.php/Archive:Urban-rural_typology.

- Faiguenbaum, S. (2011). Definiciones oficiales de «rural» y/o «urbano» en el mundo.En Dirven (dir.). Hacia una nueva definición de «rural» con fines estadísticos en América Latina. (pp. 67-107).Santiago de Chile:CEPAL. Recuperado de/Retrieved from https://repositorio.cepal.org/handle/11362/3858

- Goerlich, F., Reig, E.,\& Cantarino, I. (2016). Delimitación y características de las áreas rurales en los municipios y provincias españolas. WorkingPapers 1606, Universidad de Valencia. Recuperado de/Retroived fromhttps://ideas. repec.org/p/eec/wpaper/1606.html

- Gómez-Requena, N., Rodero-Cosado, M.L.\& Hervás-Martínez, C. (2014) Caracterización de la ruralidad utilizando métodos de inteligencia computacional en clasificación.Anales de Economía Aplicada, 28, Recuperado de/ Retrieved from http://www.asepelt.org/ficheros/File/Anales/2014/anales-2014.pdf

- INE (2011). Proyecto de los censos demográficos.En Instituto Nacional de Estadística. Madrid: Subdirección General de Estadística.

- Larrubia-Vargas, R. (1998). El espacio rural: concepto y realidad geográfica. Baetica. 20,77-95.UMA 
- Lasarte-López, J., Rodero-Cosano, M.L., \&Salinas-Pérez J.A. (2016). «La medición de la ruralidad y sus indicadores en Andalucía a través de un modelo de indicadores sociales».EnTreinta años de integración en Europa desde la perspectiva regional: balance y nuevos retos, Conferencia llevada a cabo en la XLII Reunión de Estudios Regionales (AECR). Santiago de Compostela.Recuperado de/Retrieved fromhttps://www.researchgate.net/publication/313120177

- Lois-González, R. C. (2014). As transformacións recen-tesnun rural galego.En P. Saavedra- Fernández; R.Rodríguez -González. (Dir.), A terra en Galicia: pasado presente e futuro,(pp.112 -137). Universidad Internacional Menéndez Pelayo y Concello de Lalín.

- Ley de Desarrollo Sostenible del Medio Rural (2007): Ley 45/2007, de 13 de diciembre, para el desarrollo sostenible del medio rural. Boletín Oficial del Estado, 299, de 14 de diciembre de 2007 Referencia: BOE-A-2007-21493. Recuperado de/Retrieved from https://www.boe.es/buscar/pdf/2007/BOE-A-2007-21493-consolidado.pdf.

- López-González, F. J., Crecente-Maseda, R.,\& Miranda-Barros, D. (2004). Caracterización rural de los municipios gallegos de cara a una acertada aplicación de iniciativas comunitarias de desarrollo rural. VIII Congreso Internacional de Ingeniería de Proyectos(pp. 1184-1192).Bilbao, 2004. Recuperado de/Retrieved from http://www.aeipro. com/files/congresos/2004bilbao/ciip04_1184_1192.1336.pdf

- López-Ratón, M., Santiago-Pérez, M. I. (2005). Construcción de un índice de ruralidad y clasificación de los municipios.I Congresso de Estatística e Investigação Operacional da Galiza e Norte de Portugal.Guimarães. 26-28 de octubre de2005. Recuperado de/Retrieved http://www.ige.eu/estatico/grupo_de_traballo_urbanizacion/Rural. doc

- Mora, J. (1991). El modelo de asentamientos humanos en Extremadura. EstudiosTerritoriales, 36, 129-145.

- Ocaña-Ocaña, M.C. (1993). Los municipios rurales andaluces. Población, urbanización y actividad. Boletín Económico de Andalucía, 16, 31-44.

- Ocaña-Riola, R., Sánchez-Cantalejo, C. (2005). Rurality index for small areas in Spain. Social Indicatores Research, 73, 247-266

- OCDE (1994). Creating rural indicators for shaping territorial policy. Paris. OCDE

- OCDE (2010). OECD. Regional Tipology. OECD. Paris. Recuperado de/Retrieved from https://www.oecd.org/cfe/ regionalpolicy/OECD_regional_typology_Nov2012.pdf.

- ONU (1998). Principios y recomendaciones para los censos de población y habitación. New York.

- Pietro-Lara, E., Ocaña-Riola, R. (2010). Updating rurality indez for small areas in Spain. Social Indicators Research, 95, 267-286

- Pizzoli, e. (2014).Rural development indicators for regions with different degrees or rurality. An statistical study for Italy.Recuperado de/Retrieved from https://www.researchgate.net/publication/266481995_Rural_Development_Indicators_for_Regions_with_Different_Degrees_of_Rurality_an_Statistical_Study_for_Italy.

- Sancho-Comíns, J., Reinoso-Moreno, D (2012).La delimitación del ámbito rural: una cuestión clave en los programas de desarrollo rural. Revista deEstudios Geográficos, Vol.LXXXIII, 273. 599-624 Recuperado de/Retrieved fromhttp://estudiosgeograficos.revistas.csic.es/index.php/estudiosgeograficos/article/viewFile/384/384

- UAP (Unidad de Análisis y Prospectiva) (2009). Población y sociedad. Serie Agroinfo, 12. Ministerio de Medio Ambiente, Rural y Marino.

- Vázquez, I., Sineiro, F.,\& Lorenzana, R. (2008). Tipología de municipios rurales de Galicia por indicadores socioeconómicos.12th International Conference on Project Engineering.Recuperado de/Retrieved from htt://www. usc.es/ecoagra/arquivos//Zaragoza_2008.pdf

- Waldorf, B. (2006). A continuous multi-dimensional measure of rurality: moving beyond threshold measures. American Agricultural Economics Association Annual Meeting, Long Island, California, July 24-27. Department of Agricultural Economics, Purdue University, West Lafayette, IN, USA. Recuperado de/Retrieved from https:// www.pcrd.purdue.edu/files/media/Measuring-Rurality.pdf 


\section{Sobre las autoras}

REMEdios LARrubia VARgas

Doctora en Geografía por la Universidad de Málaga. Profesora titular de Geografía Humana en la Universidad de Málaga, donde imparte docencia en las asignaturas de Fundamentos de Geografía Humana y coordina la asignatura de prácticas curriculares. Investigadora adscrita al Grupo Interdisciplinar de Estudios Rurales y Urbanos (GIERU), Grupo PAIDI HUM-1003. Las líneas de investigación han estado relacionadas con la Comercialización agraria, transformaciones recientes del espacio rural (Desarrollo rural, Mercado laboral Transferencias sociales), Agricultura ecológica, Cultivos de vanguardia, Innovaciones productivas; Servicios del Estado del Bienestar (Servicios sociales a la población, Políticas sociales y Estado del bienestar, Turismo); Poblacióninmigración. Resultado deello ha sido más de una veintena de publicaciones aparecidas en revistas indexadas internacionalmente (JCR, SCOPUS), así como una decena de libros.

Susana R. Navarro Rodríguez

Doctora en Geografía por la Universidad de Málaga y profesora titular en la Facultad de Filosofía, donde imparte docencia en los Grados de Historia y Geografía y Gestión del Territorio, y realiza labores de investigación sobre desarrollo en el medio rural, y cambios demográficos y flujos migratorios en Andalucía. Pertenece al grupo de investigación denominado «Grupo Interdisciplinar de Estudios Rurales y Urbanos (GIERU), Grupo PAIDI HUM-1003. Fruto de esta investigación son numerosos trabajos publicados en revistas indexadas en bases de datos internacionales (JCR, SCOPUS), de los que cabe resaltar «El desarrollo rural a través de las aportaciones científicas-académicas en revistas españolas (1990-2010): «Inmigración y dinámicas demográficas a comienzo del siglo XXI. Una perspectiva territorial», «Incidencia del senderismo en la economía local. Un análisis empírico a propósito del Parque Natural Sa de las Nieves». 